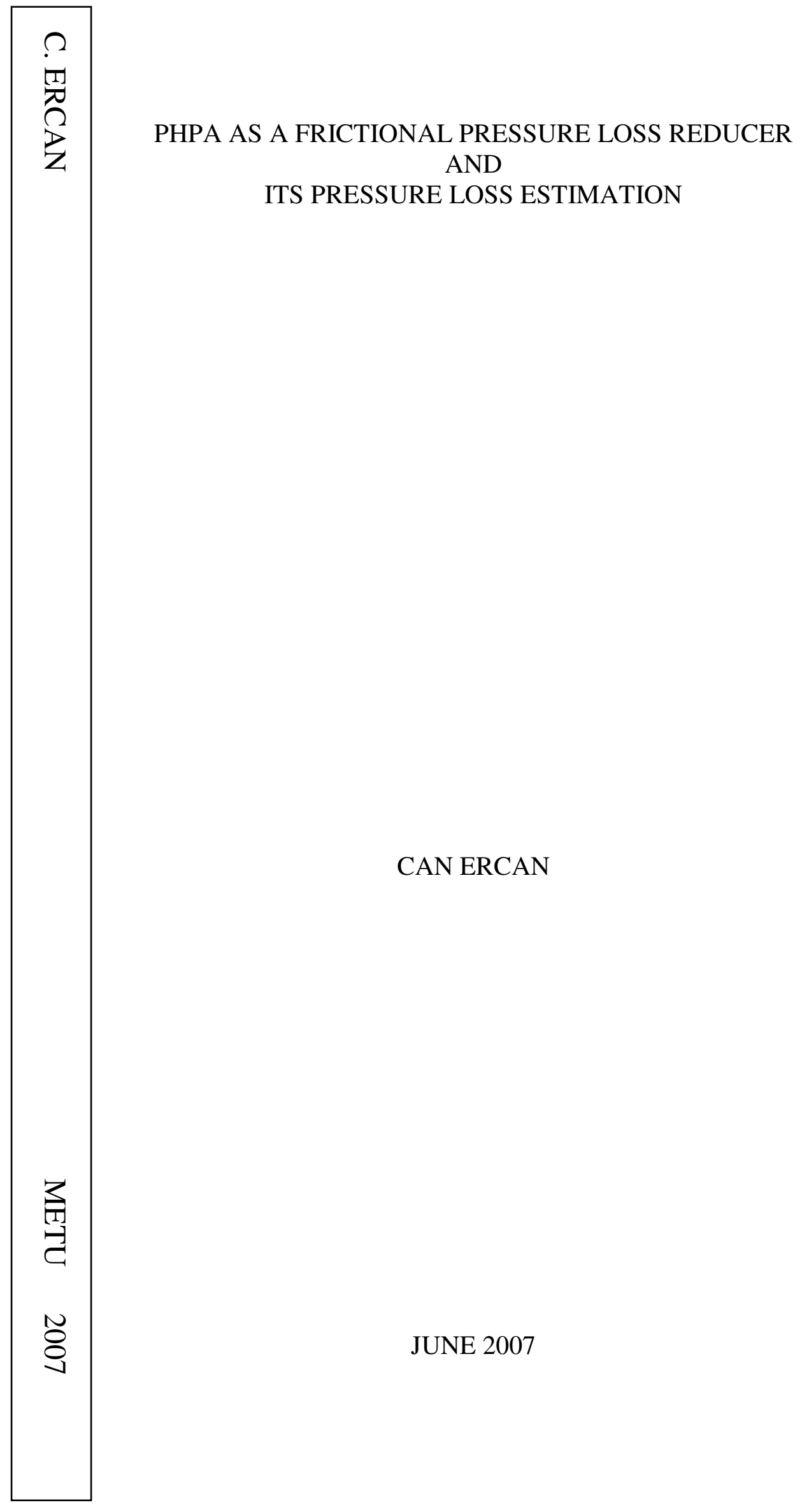




\title{
PHPA AS A FRICTIONAL PRESSURE LOSS REDUCER AND ITS PRESSURE LOSS ESTIMATION
}

A THESIS SUBMITTED TO

THE GRADUATE SCHOOL OF NATURAL AND APPLIED SCIENCES $\mathrm{OF}$ MIDDLE EAST TECHNICAL UNIVERSITY

BY

\author{
CAN ERCAN
}

IN PARTIAL FULFILLMENT OF THE REQUIREMENTS FOR

THE DEGREE OF MASTER OF SCIENCE

IN

PETROLEUM AND NATURAL GAS ENGINEERING

JUNE 2007 
Approval of the Graduate School of Natural and Applied Sciences

\section{Prof. Dr. Canan Özgen}

Director

I certify that this thesis satisfies all the requirements as a thesis for the degree of Master of Science

Prof. Dr. Mahmut Parlaktuna Head of Department

This is to certify that we have read this thesis and that in our opinion it is fully adequate, in scope and quality, as a thesis for the degree of Master of Science.

Assist. Prof. Dr. Mehmet Evren Özbayoğlu Supervisor

\section{Examining Committee Members}

Prof. Dr. Mahmut Parlaktuna

(METU, PETE)

Assist. Prof. Dr. M. Evren Özbayoğlu (METU, PETE)

Prof. Dr. Mustafa V. Kök

(METU, PETE)

Assoc. Prof. Dr. Serhat Akın

(METU, PETE)

Selçuk Erkekol, M.Sc.

(TPAO) 
I hereby declare that all information in this document has been obtained and presented in accordance with academic rules and ethical conduct. I also declare that, as required by these rules and conduct, I have fully cited and referenced all material and results that are not original to this work.

Name, Last name: Can Ercan

Signature 


\author{
ABSTRACT \\ PHPA AS A FRICTIONAL PRESSURE LOSS REDUCER \\ AND \\ ITS PRESSURE LOSS ESTIMATION \\ Ercan, Can \\ M.S., Department of Petroleum and Natural Gas Engineering \\ Supervisor : Assist. Prof. Dr. Mehmet Evren Özbayoğlu
}

June 2007, 66 Pages

As the demand of oil and gas is increasing, using the existing reservoirs more efficiently as well as searching for new reservoirs is mandatory. Most undiscovered reservoirs are in deep or ultra-deep offshore locations, where drilling to such targets are very difficult with the available fluid circulation technology, since there exists a significant frictional pressure loss due to extreme long wellbores. In order to reduce the frictional pressure losses inside the drillstring, frictional drag reducers are used. Frictional drag reducers are mostly high molecular weight linear polymer molecules and can be used with water or hydrocarbon based solvents. The system used in this study is Baroid EZ-Mud ${ }^{\mathrm{TM}}$ water solutions. Baroid EZ-Mud ${ }^{\mathrm{TM}}$ is a liquid polymer emulsion containing partially hydrolyzed polyacrylamide / polyacrylate (PHPA) co-polymer.

This study aims to observe the performance of EZ-Mud as a frictional drag reducer. For this purpose, a flow loop that consisted of a circular pipe where the frictional pressure losses can be observed under various flow rates and concentrations is developed. 
Pipe flow experiments were performed using water-based mud generated using different concentrations of Baroid EZ-Mud ${ }^{\mathrm{TM}}$ at different flow rates. Differential pressure values were recorded for each run. Rheological properties of each mud sample were determined using Fann (Couette) viscometer in order to determine the theoretical frictional pressure losses. Theoretical and measured frictional pressure losses were compared. Results showed that, as the concentration of EZ-Mud ${ }^{\mathrm{TM}}$ was increased, considerable frictional drag reduction as high as $60 \%$ was observed.

Based on the experimental data obtained from the flow loop using EZ-Mud ${ }^{\mathrm{TM}}$ with different concentrations, a friction factor correlation as a function of Reynolds Number and EZ-Mud ${ }^{\mathrm{TM}}$ concentration is developed. The proposed correlation performance was also compared with the existing correlations from the literature. It has been observed that, frictional pressure losses using the developed friction factor could be estimated within an error range of maximum $\pm 15 \%$, whereas, the existing models could not predict frictional pressure losses as accurate as the proposed model.

Keywords: Drag Reduction, Turbulent Pipe Flow, Polymer 


\title{
Öz
}

\author{
SÜRTÜNME AZALTICI OLARAK PHPA \\ VE \\ BASINÇ KAYIPLARININ HESAPLANMASI
}

\author{
Ercan, Can \\ Yüksek Lisans, Petrol ve Doğal Gaz Mühendisliği Bölümü \\ Tez Yöneticisi : Yrd. Doç. Dr. Mehmet Evren Özbayoğlu
}

Haziran 2007, 66 Sayfa

Petrol ve doğal gaz ihtiyacı arttıkça yeni rezervuarlar bulmanın yanında varolan rezervuarları daha verimli bir şekilde kullanmak da bir zorunluluk haline geldi. Birçok keşfedilmemiş rezervuar, mevcut akışkan sistem ve teknolojileri ile sondajı çok zor olan, aşırı derin offshore lokasyonlarında bulunmaktadır ve bu aşırı derin kuyularda sürtünmeden kaynaklanan kayda değer oranda basınç kayıpları oluşmaktadır. Sondaj dizisi içerisindeki sürtünmeden kaynaklanan basınç kayıplarını azaltmak için sürtünme azaltıcı maddeler kullanılır. Sürtünme azaltıcı maddeler çoğunlukla yüksek moleküler ağırlığa sahip doğrusal polimer moleküllerden oluşmaktadır ve su veya hidrokarbon bazlı çözücüler ile kullanılabilmektedir. Bu çalışmada EZ-Mud ${ }^{\mathrm{TM}}$ su çözeltileri sistemi kullanılmıştır. Baroid EZ-Mud ${ }^{\mathrm{TM}}$ bir sıvı polimer emülsiyonudur ve kısmen hidrolize olmuş polyacrylamide / polyacrylate (PHPA) yardımcı polimer içermektedir. 
$\mathrm{Bu}$ çalışmanın amacı EZ-Mud ${ }^{\mathrm{TM}}$ 'ın sürtünme azaltıcı olarak performansını incelemektir. Bu amaçla, değişen debi ve derişimlerde sürtünmeden kaynaklanan basınç kayıplarının incelenebileceği, silindir boru içeren bir akış düzeneği kurulmuştur.

Farklı derişim ve debilerdeki Baroid EZ-Mud ${ }^{\mathrm{TM}}$ ' dan oluşan su bazlı çamur ile boru akışı deneyleri gerçekleştirilmiştir. Her bir akış için basınç kaybı değerleri kaydedilmiştir. Teorik basınç kaybı değerlerini elde etmek için Fann (Couette) tipi bir viskometre kullanılarak her bir çamur örneğinin akış özellikleri belirlenmiştir. Teorik ve ölçülen basınç kaybı değerleri karşılaştırılmıştır. Sonuçlar gösterdi ki, Baroid EZ-Mud ${ }^{\mathrm{TM}}$ derişimi arttırıldıkça sürtünmeden kaynaklanan basınç kaybında \% 60'a ulaşan önemli ölçüde bir azalma meydana gelmektedir.

Farklı derişimlerde EZ-Mud ${ }^{\mathrm{TM}}$ kullanılarak gerçekleştirilen akış düzeneği deneylerinden elde edilen veriler kullanılarak, EZ-Mud ${ }^{\mathrm{TM}}$ derişimi ve Reynolds sayısının fonksiyonu olan bir sürtünme katsayısı ilişkisi geliştirilmiştir. Önerilen bu ilişkinin performansı ayrıca daha önce geliştirilmiş olan literatürdeki diğer ilişkiler ile karşılaştırılmıştır. Geliştirilen ilişkiyle elde edilen sürtünme katsayısı kullanılarak, sürtünmeden kaynaklanan basınç kayıpları en fazla \% \pm 15 hata oranı ile hesaplanabilirken, varolan diğer modeller sürtünmeden kaynaklanan basınç kayıplarını bu çalışmada önerilen ilişki kadar doğru tahmin edememektedir.

Anahtar Kelimeler: Sürtünme Azaltıcı, Türbülent Boru Akışı, Polimer 
To My Family, 


\section{ACKNOWLEDGMENTS}

I wish to express my deepest gratitude to my supervisor Assist. Prof. Dr. Mehmet Evren Özbayoğlu for his guidance, advice, criticism, encouragements and insight throughout the research.

I would like to thank Bülent Şahhüseyinoğlu (MAPEK Baroid Turkey) for providing EZ-Mud for our experiments.

I would like to express my deepest love to Nilüfer Gelmez for her encouragement, and endless support during this study.

I would also like to thank to my parents for their support. 


\section{TABLE OF CONTENTS}

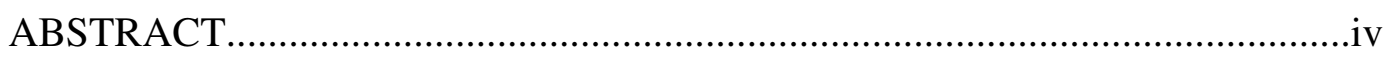

ÖZ

ACKNOWLEDGMENTS ........................................................................ viii

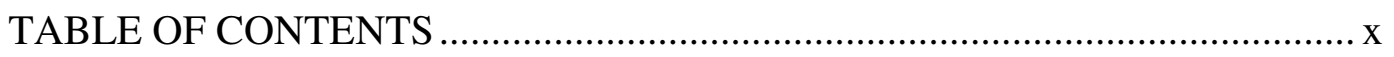

LIST OF TABLES ...............................................................................

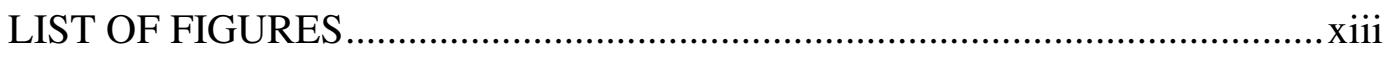

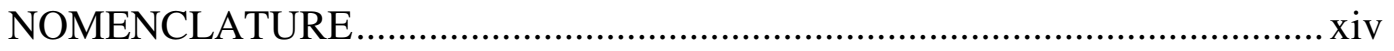

CHAPTERS

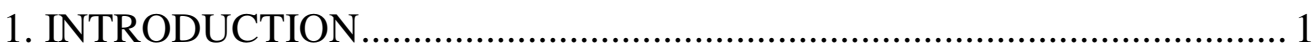

1.1 General ............................................................................... 1

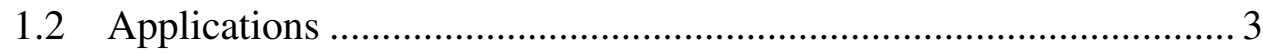

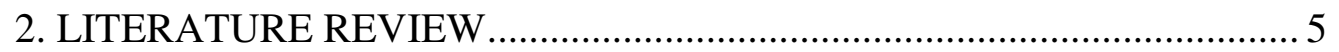

2.1 Turbulent Pipe Flow of Drag Reducing Solutions ........................... 5

2.2 Important Parameters of Drag Reduction.................................... 9

2.2.1 The Effect of Pipe Diameter.............................................. 12

2.2.2 The Effect Concentration ................................................. 12

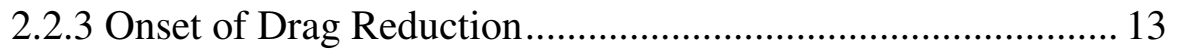

2.2.4 The Effect of Polymer Molecular Structure ............................ 14

2.3 Degradation of Polymer Molecules.............................................. 17 


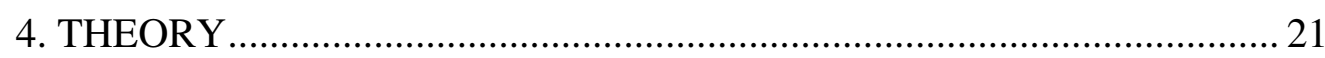

4.1 Main Parameters of Pipe Flow ..................................................... 21

4.2 Generalized Equations........................................................... 24

4.2.1 General Rheological Definition of a Fluid ............................. 24

4.2.2 General Flow Equation of Flow through Circular Pipe .......... 26

4.2.3 General Equation Parameters of Power Fluids ...................... 26

4.2.4 General Equation Parameters of Bingham Fluids ................. 27

4.2.5 Generalized Reynolds Number ............................................. 28

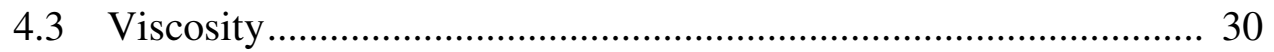

4.4 Seyer and Metzner Correlation ................................................. 32

4.5 Shaver and Merrill Correlation ..................................................... 34

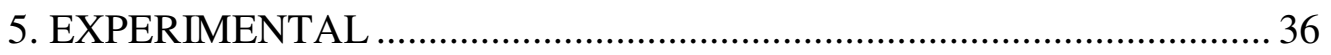

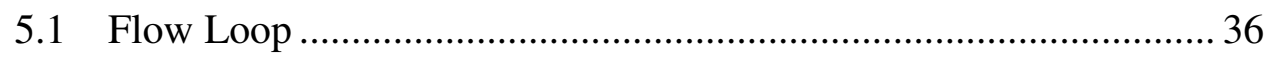

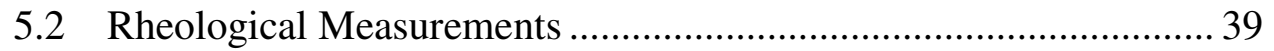

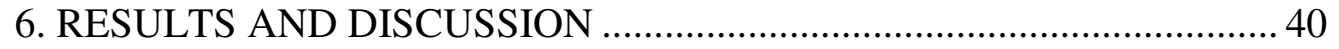

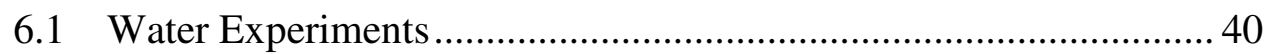

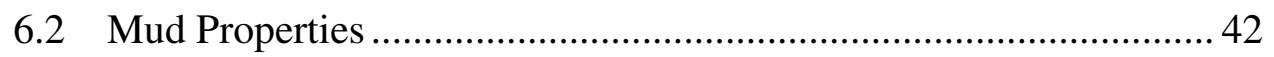

6.3 Drag Reduction Experiments .................................................... 44

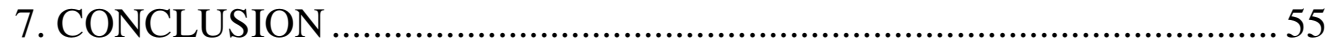

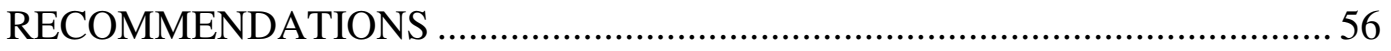

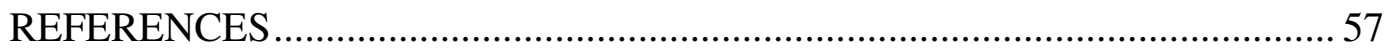

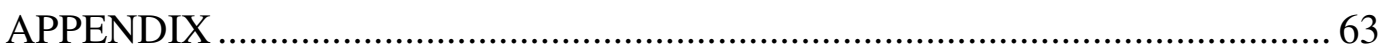




\section{LIST OF TABLES}

TABLES

4.3.1 Standard rotor-bob combination and speed settings for Model 35 Fann V-G

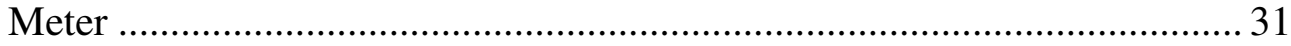

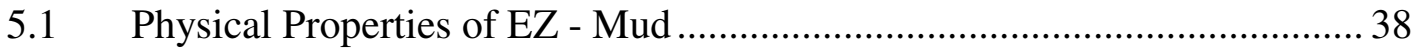

6.1.1 Absolute Percent Error for Water Data Sets ............................................. 42 


\section{LIST OF FIGURES}

\section{FIGURES}

4.1.1 Force Acting on a Fluid Element in Laminar Flow .............................. 21

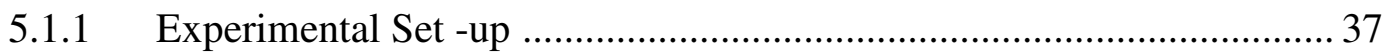

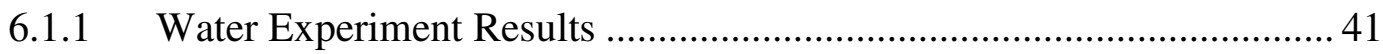

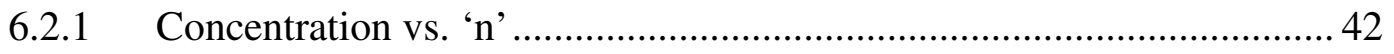

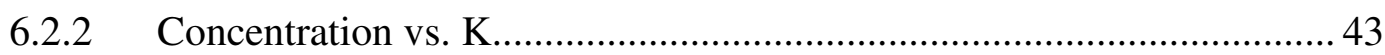

6.3.1 Flow rate vs. Measured Differential Pressure at Different

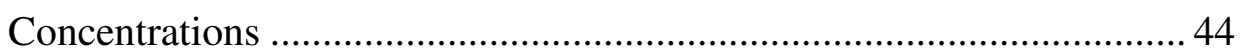

6.3.2 Concentration vs. Differential Pressure at Different Flow Rates............ 45

6.3.3 Measured vs. Calculated Differential Pressure with Bingham Model.... 46

6.3.4 Measured vs. Calculated Differential Pressure with Power Model ........ 47

6.3.5 Reynolds Number vs. Friction Factor Curves for Bingham Model ........ 48

6.3.6 Reynolds Number vs. Friction Factor Curves for Power Model ............ 49

6.3.7 Concentration vs. Percent Drag Reduction (Bingham) .........................50

6.3.8 Concentration vs. Percent Drag Reduction (Power) ............................. 51

6.3.9 Measured vs. Calculated Differential Pressure of Correlation ...............52

6.3.10 Measured vs. Calculated Differential Pressure of Seyer and Metzner ... 53

6.3.11 Measured vs. Calculated Differential Pressure of Shaver and Merrill ... 54 


\section{NOMENCLATURE}
$\mathrm{A} \quad=\operatorname{area}\left(\mathrm{ft}^{2}\right)$
$\mathrm{C}=$ concentration $(\mathrm{v} / \mathrm{v})$
$\mathrm{C}_{\mathrm{c}} \quad=$ critical concentration $(\mathrm{ppm})$
$\mathrm{DR}=$ drag reduction
$\mathrm{DR}_{(\mathrm{t})}=$ percent drag reduction at time $\mathrm{t}$
$\mathrm{DR}_{0}=$ percent drag reduction at time $\mathrm{t}=0$
$\mathrm{d}=$ diameter (in)
e $\quad=$ pipe roughness
$f_{f} \quad=$ Fanning friction factor
$\mathrm{h} \quad=$ decay constant
$\mathrm{K}=$ consistency index $\left(\mathrm{lbf}-\mathrm{s}^{\mathrm{n}} / \mathrm{ft}^{2}\right)$
$K^{\prime} \quad=$ consistency index, generalized $\left(\mathrm{lbf}-\mathrm{s}^{\mathrm{n}} / \mathrm{ft}^{2}\right)$
$K^{\prime}{ }_{v}=$ consistency index obtained from rotary viscometer $\left(\mathrm{lbf}-\mathrm{s}^{\mathrm{n}} / \mathrm{ft}^{2}\right)$
$\mathrm{K}_{\mathrm{E}} \quad=$ kinetic energy $(l b f \cdot f t)$
$\mathrm{L} \quad=$ length $(\mathrm{ft})$
$\dot{m} \quad=$ mass flow rate $(\mathrm{lbm} / \mathrm{s})$
MDR = maximum drag reduction
$\mathrm{M}_{0} \quad$ = effective number-average molecular mass at time $\mathrm{t}=0$.
$\mathrm{n} \quad$ = flow behavior index
$\mathrm{N}_{\mathrm{A}} \quad=$ Avogadro's number
$\mathrm{N}=$ flow behavior index (generalized)
$N_{\mathrm{Re}} \quad=$ Reynolds number
$N_{\mathrm{Re} G}=$ generalized Reynolds number
$\mathrm{P} \quad=$ pressure $(\mathrm{psi})$
$\Delta P=$ differential pressure (in water)
PHPA $=$ partially hydrolyzed polyacrylamide
$\mathrm{P}-\mathrm{K}=$ Prandtl - von Karman equation
$\mathrm{Q} \quad=$ flow rate $(\mathrm{gpm})$ 


$$
\begin{array}{ll}
\mathrm{R} & =\text { radius (in) } \\
\mathrm{r} & =\text { radial position (in) } \\
\mathrm{r}^{*}, \mathrm{r}^{* *} & =\text { turbulent length scales } \\
u_{T} & =\text { friction velocity } \\
U^{+} & =\text {mean velocity normalized by } u_{T} \\
\mathrm{U}_{\mathrm{d}} & =\text { turbulence energy at an infinite time } \\
v & =\text { velocity (ft/s) } \\
\mathrm{W} & =\text { average number of points per chain which undergo scission during flow } \\
y^{+} & =\text {radial coordinate normalized by inner scales, } u_{T} \text { and } v
\end{array}
$$

\section{Greek Letters}

$$
\begin{array}{ll}
\eta & =\text { Kolmogorov scale } \\
\tau & =\text { shear stress }\left(\mathrm{lbf} / \mathrm{ft}^{2}\right) \\
\tau_{\mathrm{y}}, \tau_{w} & =\text { yield shear stress, wall shear stress }\left(\mathrm{lbf} / \mathrm{ft}^{2}\right) \\
\rho & =\text { density }\left(\mathrm{lbm} / \mathrm{ft}^{3}\right) \\
\mu, \mu_{\mathrm{p}} & =\text { viscosity, plastic viscosity }(\mathrm{cp}) \\
\nu & =\text { kinematic viscosity }\left(\mathrm{ft}^{2} / \mathrm{s}\right) \\
{[\eta]} & =\text { intrinsic viscosity }(\mathrm{cp}) \\
\varepsilon & =\text { energy necessary to break one bond } \\
\theta_{600} & =\text { dial reading of viscometer at } 600 \mathrm{rpm} \\
\theta_{300} & =\text { dial reading of viscometer at } 300 \mathrm{rpm} \\
\xi & =\text { dimensionless distance from wall } \\
\mathrm{I} & =\text { dimensionless time ratio }
\end{array}
$$




\section{CHAPTER 1}

\section{INTRODUCTION}

\subsection{General}

The first attempt to understand the mechanism behind drag reduction (DR) phenomenon was performed by B.A. Toms in 1948 [1]. He has shown that addition of small amount of linear polymer (polymethylmethacrylate) in monochlorobenzene results in a lower pressure drop through pipe flow at high Reynolds numbers compared to the flow of solvent alone. Later, this phenomenon was called as "Toms Effect". Several studies $[2,7,15,17]$ followed the publication of Toms's study in order to reveal the unknown mechanism of drag reduction. Those studies are mainly based on the experimental results and the correlation of those results to obtain a theoretical background of drag reduction.

The first water soluble polymer used as a drag reducer in the literature was carboxymethylcellulose (CMC) [2]. Other polymers used as a friction reducer are polyacrylamide (PAM), polyethyleneoxide (PEO) and guar gum. They are all water soluble polymers. Other polymers such as polymethylmethacrylate (PMMA) and polyisobutylene (PIB) can also be used with hydrocarbon based solvents. Some surfactants and fibers are also discovered to have substantial drag reduction effect. It was stated that, a substantial drag reduction can be obtained with the use of suspended fibers at turbulent flow conditions and Metzner showed that drag reduction process mainly takes place at the core of the pipe and the scale of the system does not have an effect on drag reduction [3]. Although researchers and scientists paid great attention to the subject, the mechanism for the surfactants is not clearly understood yet. Qi and Zakin [4] stated that the effectiveness of cationic 
surfactant drag-reducing additives, as indicated by their effective drag-reduction temperatures and Reynolds number ranges, depends on the chemical structures and concentrations of the surfactants and counter-ions. They investigated the effects of a counter-ion's polarity, size, and chemical structure and of a surfactant's chemical structure (such as alkyl chain configuration) and head group of the surfactant on drag reduction. They found that shear induced structures (SIS) are not necessary for a surfactant to be drag reducer and rod like structures are important in surfactant drag reduction. Also viscoelasticity is not vital for surfactant drag reduction [4]. Surfactant induced drag reduction attracts attention because of the reversible degradation of surfactants on the contrary of the irreversible degradation of polymers. Hence they can be used for industrial applications more efficiently [4].

Guar is used as a drag reduction additive with respect to the stability of its molecular structure at high shear forces. Guar was used extensively through the literature by several scientists. They have achieved $80-90 \%$ drag reduction at different pipe sizes and Reynolds numbers. When shear stability is the important parameter, xanthan gum, CMC and guar gum are the main shear stable drag reducers because of their rigid backbone molecular structure. The DR efficiency of guar in deionized water by using a rotating disk apparatus has been examined and it has been found that guar is a useful, water-soluble drag reducer, more resistant to the mechanical stress than the synthetic, water-soluble drag reducer, PEO [5].

Polysaccharide xanthan gum has similar properties as guar gum. It is being produced from bacteria called xanthomonas campestris. H. J. Choi et al. [6] investigated the characteristics of polysaccharide xanthan gum as a drag reduction additive using normalizing correlations and $35.2 \%$ maximum drag reduction was calculated. They conducted their experiments with rotating disk apparatus (RDA). The normalizing correlation they used has intrinsic concentration and intrinsic drag reduction parameters which have linear relationship and the constant $\mathrm{K}$ (a parameter dependent on polymer-solvent system).

Polyethyleneoxide (PEO) is also an excellent friction drag reducer additive. Addition of small amount of polyethyleneoxide into water can create great drag 
reduction because of its high molecular weight and linear structure. Many scientists have performed experiments with PEO and water systems and they obtained very high (70-80 \%) drag reduction with only 30-40 ppm PEO. It has been also showed in other studies that drag reduction efficiency of PEO in solvents other than water, such as organic solvents or sea water, is similar to PEO-water system.

Polyacrylamide (PAM) is another effective drag reduction agent. Smith and Sitaramaiah [7] studied experimentally with different kinds of PAM and compared the drag reduction efficiency with PEO. It is pointed out that dilute solutions $(1,000$ ppm) of polyacrylamide behaves as Newtonian fluids (" $n$ " reaches to unity) in API brine and non-Newtonian behavior increases (" $n$ " decreases) when fresh water or distilled water are used as the solvent. Also for field use, polymers of 4 to 6 million molecular weight, employed at concentrations of 3 to $5 \mathrm{lb} / 1,000$ gal and at high flow rates corresponding to shear rates of 20,000 to $30,000 \mathrm{sec}^{-1}$, explained to give maximum fluid friction reduction. On the other hand, the application of those polymers is limited since they are highly shear degradable. Moreover, Choi et al. [8] investigated mechanical degradation of polyacrylamide in a rotating disk apparatus (RDA) and compared its efficiency against PEO. In their study, PAM showed higher resistance to both thermal and mechanical degradation.

Polyisobutylene have also been used for several turbulent flow studies involving the drag reduction phenomenon. Polyisobutylene was used with organic solvents such as cyclohexane, crude oil and kerosene at those studies [2,23].

\subsection{Applications}

Drag reduction additives first utilized during the hydraulic fracturing operations to pump sand with lower horsepower. Polymers are still being used during fracturing operations worldwide. Guar is commonly used during fracturing operations and Pandey [9] developed friction pressure correlations based on available surface pressure data from over 300 hydraulic fracturing operations that were carried out 
using Carboxymethylhydroxypropyl guar (CMHPG). C.B. Lester [10] compared the utilization of drag reduction polymers instead of installing additional branch to the existing pipeline system and showed that DR agents are the only quickly available short term solution to a capacity increase problem. C. B. Lester showed that drag reducing additives can result significant capacity increase of oil pipelines.

In 1971, Lescarboura et al. [11] presented a paper showing the use of high molecular weight hydrocarbon polymer called CDR and polyisobutylene at different molecular weights in 8 in. oil pipeline at Oklahoma. $25 \%$ drag reduction was achieved with the use of CDR in 8 in pipeline at 1000 wppm concentration. In 1982, Burger et al. [12] published another field study on DR application at Trans Alaska Pipeline System (48 in diameter). Use of CDR in this application resulted in a significant capacity increase, which is equal to $1 \%$ daily crude oil consumption of United States. In 1996, Berge and Solsvik [13] published another article describing the use of two types of polymer systems at Oseberg Transportation System. First tests at this system in 1991 have resulted in $50 \%$ drag reduction at $100 \mathrm{wppm}$ and increased the capacity based on company's short term requirements.

Drag reduction agents are also used in drilling mud systems. Savins [14] indicated that a project supported by National Science Foundation was realized at a deep sea drilling well including $35,000 \mathrm{ft}$ drill string to reduce circulating pressure losses. It is also pointed out that same type of applications were performed in drilling operations in Wood County Texas (1962) and at a $\mathrm{CO}_{2}$ well in Colorado (1982).

Recently most of the chemical drilling product companies are using pressure loss reduction additives in their mud systems. These systems reduce drill pipe torque and pumping pressure and can be used at temperatures as high as $120{ }^{\circ} \mathrm{C}$. The system used in our experiments is EZ-MUD, a liquid polymer emulsion containing partially hydrolyzed polyacrylamide/polyacrylate (PHPA) co-polymer and it is obtained from Baroid Industrial Drilling Products Company. 


\section{CHAPTER 2}

\section{LITERATURE REVIEW}

\subsection{Turbulent Pipe Flow of Drag Reducing Solutions}

Although it is a well known fact for almost 60 years that addition of a few parts per million of polymer can result in up to 80 percent friction drag reduction, there is no certain model comprehensively describing the mechanism of this phenomena. In this chapter, literature review of studies involving the mechanism of DR and fundamental parameters related to DR are presented.

In 1964, Savins [15] summarized the proposed mechanisms in three titles; boundary layer thickening, viscosity gradient and viscoelasticity. Boundary layer thickening model was first proposed by Oldroyd [16]. It is suggested that a layer is formed at the outer boundary of pipe which lowers the friction loss. Savins modified this Newtonian model to Non-Newtonian fluids hence defining a boundary layer coefficient. It is stated that the degree of drag reduction becomes more pronounced relatively, as the boundary layer coefficient (ratio of effective slip velocity and wall shear stress) increases.

Viscosity model is based on suppression of turbulence behavior with an unusual viscosity gradient. According to this model, viscosity of the fluid lowers the formation of vortices and eddies hence resulting in lower energy loss. Viscoelasticity is another model proposed by the earliest authors [15, 17] and it is also widely accepted. This model suggests that deformation of high molecular weight linear polymers might alter the turbulence flow behavior of the solution. 
Savins stated the fact that mechanical energy can be stored in a flexible molecule as evidenced by the long relaxation times for flow is very significant in understanding the phenomenon of drag reduction. It is also proposed that relaxation time of dilute solution should be higher than solvent in order to obtain drag reduction.

Seyer and Metzner [17] studied on the turbulent structure in the wall region based on the model of Townsend-Bakewell to obtain a correlation of friction factor for viscoelastic systems. In this study, elasticity of the polymer molecules was accounted through the use of relaxation time, polymer characteristics and concentration. Besides, a photographical study was performed showing the low velocity gradient, large radial fluctuations and thin wall region across the pipe cross section of Newtonian turbulence and for drag reducing system lower fluctuations and higher velocity gradient were observed.

Shaver and Merrill [2] used CMC dilute solutions and also performed photographic dye-injection experiments. Dye injection at the wall of the tube of Newtonian fluids showed formation of vortices at the wall and these vortices move inside the core hence creating turbulence across the pipe cross section. For the CMC solutions, dye injection at the wall showed that the layer near the wall was thicker than the Newtonian fluids in turbulent flow. Also, formation of vortices was lowered and the flow in the core was less disturbed by these vortices. However, Shaver and Merrill did not accept the existence of plug flow (a result of slippage at the wall) based on their velocity profile results. It was explained that vortices created at the wall of the pipe at the lowest viscosity moves inward to the core of the pipe at the highest viscosity and this results as a dampening of the effect of vortices and less turbulence. This model was explained with the concept of periodic boundary layers of Richardson [18]. However, this model was not sufficient to explain the decrease in the number of vortices created at the wall.

Meyer [19], proposed a friction factor Reynolds number correlation based on two parameters which account the elastic properties of polymer solute and concentration. Viscoelasticity was accepted as the main mechanism creating the 
drag reduction and Meyer described that at a critical shear stress, polymer molecules stores the turbulence energy elastically hence reduction of turbulence occurs.

Studies showed that, mechanism of drag reduction can not be described with single wall layer effect or viscoelasticity. Taylor and Middleman [20] demonstrated that the mechanism of drag reduction which entirely relies on wall adsorption of the polymer molecules is incomplete. They investigated the dispersion of a dye stream which is injected at the pipe center of the polyetyhyleneoxide system. It was observed that dye plume in polyethyleneoxide was narrower and also more intermittent than in water. Dampening of the small scale turbulence motion across the pipe cross section is also reported at this study. Large scale, low frequency motion was observed for PEO solution at turbulence from the dye streak photographs again for the study of Taylor and Middleman. As a result, effect of drag reducing polymers at the pipe center of the flow was demonstrated and it is proposed that not only the polymers reduce turbulence at the wall but also reduces at the core.

Astarita and Nicodema [21] used pitot tube measurements to understand the velocity distribution at the turbulent pipe flow and derived some equations to better evaluate the obtained experimental pitot tube readings. It is stated that elastic effects in the central region of the tube are much larger than at the wall.

The difference between calculated and measured friction factors for drag reducing polymer systems led the scientists to obtain better correlations to account for the proposed elastic behavior of polymer molecules. Patterson and Zakin [22] derived a quantitative expression for the reduction of turbulent energy dissipation during drag reduction based on the Maxwell model. The proposed mechanism involved the viscous deformation with increasing shear stress, and the recovery of this elastic deformation upon removal of the shear stress. Hence, turbulent energy dissipation reduction mechanism was quantitatively presented, without the assumption of a reduction of turbulence intensity, at the study of Patterson and Zakin. However, considerable differences were observed between the measured 
and calculated drag reduction values with this model because of the some other assumed parameters.

Another viscoelastic model was proposed by Rodriguez et al. [23] based on the Maxwell model and experimental results with non-polar solvents were correlated well. A modified Deborah number, $\left(\tau_{1} \cdot \mathrm{v}\right) / d^{0.20}$, was used to obtain a unique curve which accounts the diameter, velocity and concentration effects and $f / f_{p v}$ vs. modified Deborah number was plotted, where $f$ is friction factor for drag reduction, $f_{p v}$ is for no drag reduction, $\tau_{1}$ is first mode relaxation time, $\mathrm{v}$ is velocity and $\mathrm{d}$ is diameter, for different non-polar solvent systems and for other polar solvent systems which were obtained from the literature. They found a unique curve representing the degree of drag reduction for different systems.

Gordon [24] proposed a mechanistic model by improving a model for Newtonian fluids. A molecular dumbbell model was then utilized and a correlation was proposed and compared with the work of Rodriguez, Zakin and Patterson [23]. It was suggested that turbulent drag reduction in dilute polymer solution is a result of the resistance of these systems to dispersion or breakup. To demonstrate the constancy of viscosity and elastic effects of normal stresses a dynamic viscosity the dumbbell model was utilized. Hence a unique correlation was obtained for any particular solution to estimate friction ratio.

Landahl [25] improved the two scale model which was composed of large scale motions, convected disturbances and small-scale disturbances resulting from the secondary stability of the large scale motion. In this paper it was stated that the major dynamical effect of polymers would be to cause stabilization of secondary inflectional instability and thereby inhibit turbulence production. Viscoelasticity was proposed to be a minor effect to cause drag reduction. Anisotropic stress caused by the extension of the molecular coils at high shear stress is emphasized to be the major effect of turbulence stabilization. 
Darby and Chang [26] obtained a generalized correlation for friction factor which accounts for nonlinear viscoelastic properties of the solutions which was applicable to Newtonian and Non-Newtonian solutions. Drag reduction mechanism was explained such that in time dependent deformations energy was stored by elastic properties and lost by viscous properties. Since turbulence was locally time dependent, and polymeric fluids were viscoelastic, energy stored by elastic properties would represent a reduction in the amount of energy which would otherwise be dissipated by viscous forces. Parameters required for the proposed correlation of Darby and Chang were only elastic and viscous rheological parameters.

\subsection{Important Parameters of Drag Reduction}

Virk et al. [27] found that drag reduction occurs at a certain wall shear stress. This point is called onset of drag reduction and it is related to random-coil size diameter of the polymer in solution. Virk also proposed the idea of maximum drag reduction (MDR). It was explained that the maximum friction reduction is limited by an asymptote which is independent of polymer and pipe diameter.

Mean velocity profile is divided into three parts by Virk [28]; the viscous sublayer, an elastic sublayer and outermost region. Viscous sublayer is described as the region without drag reduction where the polymer solutions obey the same friction factor correlation as solvent. Elastic sublayer is described as the region where the friction factor relation depends on all polymeric parameters, the polymer solvent system such as polymer molecular weight and concentration. Furthermore an asymptotic regime which reveals the maximum drag reduction possible in turbulent flow was explained. This maximum drag reduction asymptote is independent of polymeric parameters. Virk also accepted that the effect of polymer on turbulence is more pronounced at the bounding wall than the core section. 
The elastic sublayer model of Virk [29] can better be presented at a plot of $\left(1 / f_{f}^{0.5}\right)$ vs. $\log \left(N_{\mathrm{Re}} \cdot f_{f}^{0.5}\right)$. In this graph drag reduction area is bounded between Virk's maximum drag reduction asymptote(5) and Prandtl-von Karman(2) equation for Newtonian turbulent pipe flow. These equations are as follows [29];

The equation for the laminar flow of polymer solutions:

$f_{f}^{-0.5}=\frac{N_{\mathrm{Re}} \cdot f_{f}^{0.5}}{16}$

The equation for Prandtl-von Karman Law of Newtonian turbulent flow, which represents the zero drag reduction boundary:

$$
f_{f}^{-0.5}=4.0 \cdot \log _{10}\left(N_{\mathrm{Re}} \cdot f_{f}^{0.5}\right)-0.4
$$

The equation derived for the polymer turbulence interaction region:

$$
f_{f}^{-0.5}=(4.0+\delta) \cdot \log _{10}\left(N_{\mathrm{Re}} \cdot f_{f}^{0.5}\right)-0.4-\delta \cdot \log _{10}\left(\sqrt{2} d W^{*}\right)
$$

Where $\delta$ and $\mathrm{W}^{*}$ are called slope increment and onset wave number respectively. Slope increment is described as the amount of difference between the slopes of P$\mathrm{K}$ law and polymeric solution after the onset of drag reduction.

And the maximum drag reduction asymptote:

$$
f_{f}^{-0.5}=19.0 \cdot \log _{10}\left(N_{\mathrm{Re}} \cdot f_{f}^{0.5}\right)-32.4
$$

A power law expression (approximation) for the maximum drag reduction asymptote is:

$$
f_{f}=0.58 \cdot N_{\mathrm{Re}}^{-0.58} \quad \text { for } \quad 4,000<N_{\mathrm{Re}}<40,000
$$


Although PEO was used to obtain equations above, several experimental data from the literature were used to check the accuracy of this correlation and the data mostly agree well with those curves.

Mean velocity profiles of Virk are listed below. For the viscous sublayer:

$U^{+}=y^{+}$

And for the velocity profile, at maximum drag reduction:

$U^{+}=11.7 \cdot \ln y^{+}-17.0$

Newtonian Wall Law, at zero drag reduction:

$U^{+}=2.5 \cdot \ln y^{+}+5.5$

Where,

$U^{+}=\left(U / u_{T}\right)$,

and

$$
y^{+}=\left(y \cdot u_{T}\right) / v .
$$

Similar to the friction factor vs. Reynolds number correlations for MDR and P-K law above, mean velocity profile equations reveal three regions of flow characteristics. When $\left(\mathrm{U}^{+}\right.$vs. $\left.\log \mathrm{y}^{+}\right)$is plotted, depending on the drag reduction properties of the polymer solvent system, turbulent flow velocity profile curve at a certain Reynolds number falls between the MDR and P-K curves. Again it was stated that the experimental observations agree well with mean velocity profiles.

Based on this model polymer turbulence interaction takes place at elastic sublayer region and it involves the production of turbulent strain energy. 


\subsubsection{The effect of pipe diameter}

Savins [15] defined the diameter effect as the decrease of drag reduction with increasing pipe diameter, when the same polymer solvent system was used. This issue creates serious problems when comparing different data of different sources in the literature because data obtained with certain diameter can not be extrapolated easily to a larger diameter pipe.

In the P-K coordinate $\left(N_{\operatorname{Re}} \sqrt{f_{f}} v s .1 / \sqrt{f_{f}}\right)$ the effect of pipe diameter can easily be observed. As the pipe diameter increases, onset of drag reduction occurs at a higher $\left(N_{\operatorname{Re}} \sqrt{f_{f}}\right)$ [29]. Accordingly, onset of drag reduction occurs at a certain wall shear stress.

When it is desired to compare different systems at various pipe sizes, in order to minimize the diameter effect, drag reduction vs. friction velocity for the untreated (additive free fluid) plot is utilized [14]. Similar to this procedure Whitsitt et al. [30] proposed a correlation with solution friction velocity and drag reduction based on the assumption that wall shear stress is the main drag reduction mechanism but the correlation of Savins [15] resulted in better results.

\subsubsection{The Effect of Concentration}

Drag reduction increases with increasing concentration up to a limiting asymptote called maximum drag reduction curve and then the increase of viscosity suppresses the drag reduction effect of the system hence pressure drop increases. Virk [29] stated that the slope increment at the P-K coordinate system of a certain polymer system is directly proportional to the square of concentration. There are several studies involving different concentrations of different polymers and up to $80 \%$ DR can be obtained at concentrations between 10 to $100 \mathrm{wppm}$ at certain 
pipe sizes. Because of the phenomenon of "diameter effect", higher concentration is required for the same DR at a larger diameter pipe. Hoyt [31] presented a table showing the concentrations required for $67 \%$ DR at a Reynolds number of 14000 , 400 wppm required for guar, 850 wppm required for gum karaya, 10 wppm required for Polyox WSR-301 and 20 wppm required for Polyacrylamide (Polyhall 295).

\subsubsection{Onset of Drag Reduction}

Polymer molecules delay the transition of laminar flow to turbulent flow. After a threshold shear stress, friction reduction effect takes place resulting in lower friction factor than expected at that Reynolds number [29]. This point is called onset of drag reduction and it depends on molecular weight, polymer random-coil size in solution. This relation is presented as following by Virk:

$$
R_{G}{ }^{a} \cdot T_{w}{ }^{*}=\Omega_{T}
$$

Where; $\mathrm{R}_{\mathrm{G}}$ is the polymer random coil size, $\mathrm{nm}$

$\mathrm{T}_{\mathrm{w}}{ }^{*}$ is onset wall shear stress, $\mathrm{N} / \mathrm{m}^{2}$

$\Omega_{\mathrm{T}}$ is onset constant

Onset constant depends on polymer species and solvent. (An average value of $10 \times 10^{6}$ was suggested by Virk [29] for PEO, PAM and PIB)

Sreenivasan and White [32] explained the onset of drag reduction through the elastic theory. For very small concentrations, the scale $r^{* *}$ will be smaller than $\eta$, and so the polymer will have no effect on turbulence. There exists a minimum concentration for which $r^{* *}=\eta$, at which the polymer effects will begin to be just felt. This corresponds to the onset of drag reduction. $r^{*}$ is the turbulent length scale of the system at which turbulent time scale is equal to characteristic time scale of the polymer. The elastic theory, according to this definition, supposes that in a 
certain scale range, $\mathrm{r}^{* *}<\mathrm{r}<\mathrm{r}^{*}$, the polymers are stretched a little and all the flow scales between this range remain unaffected by the polymer.

Turbulence scales smaller than $r^{* *}$ are strongly affected by the elastic forces. $\eta$ is the Kolmogorov scale replaced with $r$ in the equation of time scale, to obtain the smallest characteristic time scale in turbulence. Further to this definition, Sreenivasan and White [32] stated that as the concentration is increased further, the characteristic scale $\mathrm{r}^{* *}$ approaches and equals to $\mathrm{r}^{*}$, so that slight amount of stretching may change the elastic energy equal to the kinetic energy at this common scale. It is also possible that the increased concentration may initiate coils of polymer molecules to interact, so that the turbulent rate-of-strain becomes an ineffective stretching mechanism. Besides, for inhomogeneous, concentrated flow, local strain rates may be so high at some places that the polymers are fully extended and elongational viscosity may indeed dominate.

\subsubsection{The effect of polymer molecular structure}

Virk [29] defined an intrinsic slope increment which was dependent on the number of backbone chain links of the polymer molecule and depicted that they are directly proportional to each other. Virk supported this theory with studies on PEO, PAMH, PAM, PIB and other linear polymer molecules. Polymer random coil size is also an important parameter as it is mentioned before. Experiments performed with polymer-water systems show better drag reduction than polymerbrine systems.

Savins [14], states that molecular characteristics include molecular weight, molecular rigidity and entanglement capacity. A Polymer with linear flexible chains has lower rigidity than that of a polymer composed of a rigid backbone with stiff side chains. For a constant molecular weight and concentration a synthetic polymer molecule comprised of fairly flexible chains and few side groups should yield more drag reduction activity in deionized water than a molecule comprised 
of a rigid backbone with steric hindrance from bulky side chains or pendant groups.

Liaw, et al. [33] studied the effects of molecular characteristics on polymer drag reduction. They performed experiments with $0.0328,0.0652$ and 0.107 in. inner diameter pipes with polydimethyl siloxane, polyethylene oxide, polyisoprene, polybutadiene, polyisoprene, ethyl (cellulose) and a copolymer of epichlorohydrin and ethylene oxide at different molecular weights and concentrations. A critical concentration of $\mathrm{C}_{\mathrm{c}}$ was defined as the concentration which separates the dilute and concentrated solutions. Above $\mathrm{C}_{\mathrm{c}}$ friction factor vs. Reynolds number plot shows a deviation from an extension of the laminar line with no transition region. $\mathrm{C}_{\mathrm{c}}$ is stated to be increasing with tube diameter. Also $\mathrm{C}_{\mathrm{c}}[\eta]$ is explained to be less sensitive to molecular weight variations and can be utilized to compare DR effectiveness of different polymers. It was demonstrated that $C_{c}[\eta]$ for equal molecular weight polymers is a function of molecular structure. As the polymer molecule becomes less flexible, the rigidity factor (mean square of end to end distance of polymer molecules at different conditions) increases and $\mathrm{C}_{\mathrm{c}}[\eta]$ for a certain tube size increases. The critical chain entanglement molecular weight must exceed about 50 for efficient drag reduction even for low rigidity factor values. Moreover, all turbulent friction factor values are correlated for the region above $\mathrm{C}_{\mathrm{c}}$ with a single function of $f / f_{p v}$ vs. $N_{R e}$, where $f$ is drag reduction friction factor and $\mathrm{f}_{\mathrm{pv}}$ is no drag friction factor. At high Reynolds number $\mathrm{f} / \mathrm{f}_{\mathrm{pv}}$ approaches to 0.25 .

Recent studies on drag reduction make use of Direct Numerical Simulation (DNS) in order to evaluate different proposed mechanisms of turbulent flow of viscoelastic fluids. Toonder et al. [34] performed both DNS and laser Doppler velocimetry (LDV) studies to check the theories involving stress anisotropy and elasticity in turbulent pipe flow of dilute polymer solutions. The effect of viscous anisotropy caused by the polymer orientation and the extension of this model with an elastic component were simulated with DNS. The results of these simulations have been compared with the results obtained experimentally with the LDV. It was concluded that the important property of drag reduction by polymer additives is related to a purely viscous anisotropic stress caused by extended polymers and the 
elastic behavior reduces the drag reduction effectiveness. Hence, the rod-like shape of the elongated polymer molecules explained to be the major factor of this stress anisotropy similar to the already elongated shape of the fibers. At that point the mechanism proposed is similar to the mechanism proposed by Landahl [25]. Landahl also proposed that if stretched strongly by the mean shear flow, polymer structures will have an overall effect on unsteady perturbations qualitatively similar to that of almost rigid elongated particles suspended in the fluid. But the aspect ratio of the polymer molecules is much higher than the fibers so that they are more effective drag reducers. However the viscoelastic model of Toonder does not support shear waves.

Khomami et al. [35] also utilized direct numerical simulation to develop relationships between turbulent channel flow of dilute polymer solutions and fluid rheological parameters such as maximum chain extensibility, Reynolds number, and weissenberg number and drag reduction. It was stated that large polymer extensibility and high weissenberg numbers (a dimensionless group relating the first normal stress difference to the shear stress, both evaluated at the wall shear rate) are required to obtain high drag reduction. Moreover, it is stated that polymer molecules are extracting energy by stretching from the flow hence reducing the turbulent fluctuations.

Besides the drag reduction with polymers, surfactants are also proved to be effective additives resulting in high turbulent suppression. Unlike the irreversible degradation of polymers, surfactants can be reform their structure after mechanical degradation hence they are more utilized in industrial applications. However, the mechanism of drag reduction of surfactant systems is not understood well. Surfactants are usually organic compounds that are amphiphilic, meaning they contain both hydrophobic groups and hydrophilic groups. Therefore, they are soluble in both organic solvents and water. Surfactants contain two parts; the tail which is soluble in hydrocarbons or any other oleophilic environment and the head group which is soluble in water or another hydrophilic environment. 
Surfactants are classified as; Ionic (Anionic and Cationic), Zwitterionic and nonionic [36]. In an aqueous environment surfactants adsorb to interfaces and at a certain concentration called critical micelle concentration, the monomers aggregate in bulk solution to form micelles. Orientation of these micelles along the shear and flow direction results in the formation of shear induced structures (SIS). The reversible shear degradation of surfactants comes from the reformation of these micelles after being destroyed.

Myska and Zakin [37] investigated the differences in the flow behavior of polymeric and cationic surfactant drag reducing additives. They showed that relaxation time of micelles is a function of surfactant-counterion system, the concentration, the shear applied and the temperature. Polymers show shear thinning behavior whereas surfactants form shear induced structures. Reversible degradation of surfactant structures at high shear rates (critical shear rate) and a gradual deviation from the laminar flow curve are other differences between surfactant and polymeric solutions. Besides, friction factors below the MDR asymptote for the polymers can be obtained with cationic surfactants. The existence of a different mechanism than the polymeric solutions was also proposed. Moreover, Zakin et al. [38] showed that non-viscoelastic surfactants can be drag reducing contradicting the general belief that there is a correlation between viscoelastic properties and drag reduction and the extensional viscosity is the key property to correlate with drag reduction effectiveness.

\subsection{Degradation of Polymer Molecules}

Degradation studies are important for understanding the mechanism behind polymer drag reduction. For that purpose, researchers performed several studies on polymer degradation in turbulent flow. Hanratty et al. [39] performed some experimental studies on polyacrylamide solutions in turbulent channel flow. Molecular weight distribution of polyacrylamide solution after mechanical degradation was investigated experimentally using gel permeation 
chromatography (GPC). Long time intervals were observed for three different solutions over which the molecular weight distribution remained unchanged even though drag reduction was decreasing. Accordingly, polymer aggregation was proposed to be the key factor of a drag reduction mechanism. Drag reduction is commonly believed to be strongly affected by the concentration of molecules in the high end of the molecular weight distribution and that the loss in drag reduction is directly related to a reduction in their number due to degradation. However, the results of their study do not support this idea since in regions where the concentration of the high molecular weight tail $\left(\mathrm{MW}>5 \times 10^{6}\right)$ varies by a factor 3.5 (from 20 to $70 \mathrm{ppm}$ ), the drag reduction remains nearly constant (varying from 34 to $38 \%$ ).

Kalashnikov [40] studied with aqueous solutions of PEO and solutions of PIB in kerosene with a rotational apparatus and explained the degradation procedure simply. The cohesive forces create cross-links between the polymer molecules in the liquid-crystalline phase. Just as it was supposed for interactions between macromolecules in solid polymers, due to co-operative effects, the energy of these cross-links becomes of order of the covalent bond energy. This is why the disturbances characterized by sufficiently high deformation rates will create the conditions for the break of the chemical bond in macromolecules of the liquidcrystalline phase occupying the connected space. Only when the liquid-crystalline phase occupies the connected space, the possibility of developing the stresses sufficient for the scission of chains arises in this phase under the action of various disturbances. When the connectedness is lost, destruction stops.

Choi et al. [41] performed experiments on different concentrations of polystyrene dilute solutions with their rotating disk apparatus. They have also used different type of solvents in order to observe the degradation dependence on solvent quality. It was observed that drag reduction decreases with time due to the degradation of polymer molecules in turbulent flow. Also, it was reported that polymer molecules degraded faster in a poor solvent at low Reynolds number. Polystyrene molecular weight in benzene showed lower degradation in turbulent flow in rotating disk apparatus. The statistical model below of Brostow [42] was adapted to the data 
obtained by Choi and obtained an excellent fit. The equations suggested are as follows;

$$
\begin{aligned}
& \frac{D R_{(t)}}{D R_{0}}=\frac{1}{1+W\left(1-e^{-h t}\right)} \\
& W=\frac{M_{0} U_{d}(\infty)}{C \cdot N_{A} \varepsilon} .
\end{aligned}
$$




\section{CHAPTER 3}

\section{STATEMENT OF THE PROBLEM}

Several studies performed in the literature to understand different aspects of drag reduction since the study of Toms's in 1948. The aim of these studies was to determine the effects of different parameters on the amount of drag reduction. For this purpose mostly simple but efficient pipe flow experiments were performed in most of those studies and several correlations were proposed for the effect of each variable. As a result of these early studies it was revealed that this phenomenon is not a simple problem and the amount of drag reduction depends on several parameters. Accordingly, several other researchers were interested in this complex subject and enhanced previous experimental studies to better understand the mechanism and theory behind drag reduction.

This phenomenon received attention because it has significant industrial benefits, especially in the oil industry. Considerable amount of increase in oil pipeline capacities were recorded and published. Polymers are also used in hydraulic fracturing operations and drilling operations to reduce the pressure loss due to skin friction. Accordingly, calculation of pressure losses through the pipeline or drill pipe with the addition of a certain amount of drag reduction additive has become an important issue.

The aim of this study is to demonstrate drag reduction capacity of dilute solutions of EZ-Mud ${ }^{\mathrm{TM}}$ particularly, with turbulent pipe flow experiments and to propose a correlation to estimate differential pressure losses based on experimental data for different concentrations. This correlation was also compared with other correlations from the literature. 


\section{CHAPTER 4}

\section{THEORY}

\subsection{Main Parameters of Pipe Flow}

In this chapter, all of the necessary correlations and definitions of parameters are included for fluid flow calculations in pipes with the theoretical and experimental background.

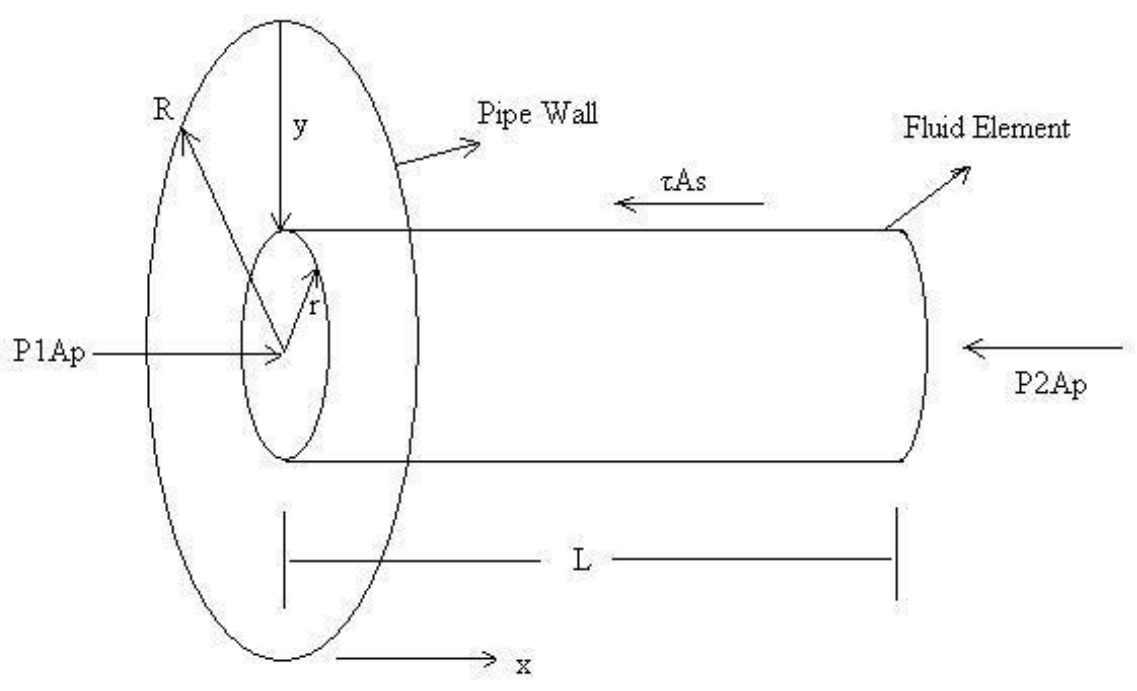

Figure 4.1.1 - Forces acting on a fluid element in laminar flow

Forces acting on a fluid element in circular pipe flow are illustrated at the Figure 4.1.1 and can be stated with the equations below [43]: 
$\Sigma \mathrm{F}_{\mathrm{x}}=\mathrm{Ma}=0$,

Which is true for steady state flow of incompressible fluid, and

$\mathrm{P}_{1} \mathrm{~A}_{\mathrm{p}}-\mathrm{P}_{2} \mathrm{~A}_{\mathrm{p}}-\tau \mathrm{A}_{\mathrm{s}}=0$

where $A_{p}$ and $A_{s}$ are the area perpendicular to the flow and the surface area of the fluid element respectively. Then,

$\left(\mathrm{P}_{1}-\mathrm{P}_{2}\right)\left(\pi \mathrm{r}^{2}\right)=\tau(2 \pi \mathrm{rL})$

$\tau=\frac{\Delta \mathrm{Pr}}{2 L}$

Wall shear stress is

$\tau_{\mathrm{w}}=\frac{\Delta \mathrm{Pd}}{4 L}$

And the friction factor defined as the ratio of wall shear stress to the kinetic energy per volume of a fluid element, hence;

$\mathrm{K}_{\mathrm{E}}=\frac{\rho v^{2}}{2}$

$f_{f}=\frac{\tau_{w}}{K_{E}}=\frac{2 \tau_{w}}{\rho v^{2}}$

Combining the equations of $\tau_{\mathrm{w}}$ and $f_{f}$

$\frac{\Delta P}{\Delta L}=\frac{\left(2 f_{f} \rho v^{2}\right)}{d}$ 
The above form of Darcy-Weisbach equation is called Fanning equation and can be used to calculate the pressure drop if the fanning friction factor at turbulence or laminar flow is obtained.

In order to determine the flow regime, Reynolds number is used. Reynolds number can be obtained using Buckingham- $\pi$ theorem depending on the flow variables like $\mathrm{v}$ (velocity), $\mathrm{d}$ (pipe diameter), $\rho$ (fluid density), $\mu$ (viscosity). Since there are seven variables depending each other and three dimensions, $t$ (time), $\mathrm{m}$ (mass) and L (length), four dimensionless $\pi$ terms will be required to express the functional relationship between pressure drop and the remaining set of variables [43].

$\Delta \mathrm{P}=\varphi(\mathrm{d}, \rho, \mathrm{v}, \mu, \mathrm{L}, \mathrm{e})$

$\pi_{1}=\left(\rho^{\mathrm{a} 1} \mathrm{v}^{\mathrm{b} 1} \mathrm{~d}^{\mathrm{c} 1}\right) \Delta \mathrm{P}$

$\pi_{2}=\left(\rho^{\mathrm{a} 2} \mathrm{v}^{\mathrm{b} 2} \mathrm{~d}^{\mathrm{c} 2}\right) \mu$

$\pi_{3}=\left(\rho^{\mathrm{a} 3} \mathrm{v}^{\mathrm{b} 3} \mathrm{~d}^{\mathrm{c} 3}\right) \mathrm{e}$

$\pi_{4}=\left(\rho^{\mathrm{a} 4} \mathrm{v}^{\mathrm{b} 4} \mathrm{~d}^{\mathrm{c} 4}\right) \mathrm{L}$

Solving for $\mathrm{a}, \mathrm{b}$, c from the set of equations obtained results in the following relations:

$\pi_{1}=\Delta \mathrm{P} / \rho v^{2}$,

$\pi_{2}=\mu / \rho v d$,

$\pi_{3}=\mathrm{e} / \mathrm{d}$,

$\pi_{4}=\mathrm{L} / \mathrm{d}$.

Combining the equations according to the relation, $\pi_{1}=\varphi\left(\pi_{2}, \pi_{3}, \pi_{4}\right)$, the following relation can be obtained.

$$
\frac{\Delta P}{\rho}=\varphi\left(N_{\mathrm{Re}}, \frac{e}{d}, \frac{L}{d}\right) v^{2}
$$


The only parameter which contributes to drag reduction calculations is Reynolds number and as a result it is defined as;

$$
\frac{1}{\pi_{2}}=N_{\mathrm{Re}}=\frac{\rho v d}{\mu} .
$$

\subsection{Generalized Equations}

General rheological definition of a fluid and general equation of flow through circular pipe were presented in this section with the methods of their derivation.

\subsubsection{General Rheological Definition of a Fluid}

Following results can be obtained by using Rabinowitch-Mooney approach [44, 45]. Mass flow rate is

$$
\dot{m}=\bar{Q} \cdot \bar{\rho}
$$

Where flow rate can be stated as below based on the Figure 4.1.1,

$$
\bar{Q}=\int_{0}^{2 \pi} \int_{0}^{R} v r d r d \theta=-\pi \int_{0}^{R} r^{2} d v
$$

Where $d v=-f(\tau) \mathrm{dr}$ and $f(\tau)$ is the shear rate function for a certain rheological model and

$$
\frac{\tau}{\tau_{\mathrm{w}}}=\frac{r}{\mathrm{R}} \rightarrow d r=\frac{R}{\tau_{\mathrm{w}}} d \tau
$$

General flow equation can be obtained upon substituting the variables above(35) into Equation(34), 
$\bar{Q}=\pi\left(\frac{R}{\tau_{\mathrm{w}}}\right)^{3} \int_{0}^{\tau_{\mathrm{w}}} \tau^{2} f(\tau) d \tau$

After differentiating both sides of the equation with respect to $\tau_{\mathrm{w}}$ and integrating,

$f\left(\tau_{\mathrm{w}}\right)=\left(-\frac{\partial v}{\partial r}\right)=\frac{3 \bar{Q}}{\pi R^{3}}+\tau_{\mathrm{w}} \frac{\partial}{\partial \tau_{\mathrm{w}}}\left(\frac{\bar{Q}}{\pi R^{3}}\right)$,

and substituting flow rate,

$\bar{Q}=\frac{\pi}{4} d^{2} v$.

Hence the equation below can be obtained.

$f\left(\tau_{\mathrm{w}}\right)=\frac{3}{4}\left(\frac{8 v}{d}\right)+\frac{1}{4}\left(\frac{d}{4} \frac{\Delta P}{\Delta L}\right) \frac{\partial\left(\frac{8 v}{d}\right)}{\partial\left(\frac{d}{4} \frac{\Delta P}{\Delta L}\right)}$

This equation can be simplified by defining the variable " $\mathrm{N}$ ".

$f\left(\tau_{w}\right)=\left(-\frac{\partial v}{\partial r}\right)=\left(\frac{8 v}{d}\right)\left[\frac{3 N+1}{4 N}\right]$

where $\mathrm{N}$ is

$N=\frac{\partial \ln \left(\frac{d}{4} \frac{\Delta P}{\Delta L}\right)}{\partial \ln \left(\frac{8 v}{d}\right)} \rightarrow \frac{1}{N}=\frac{\partial \ln \left(\frac{8 v}{d}\right)}{\partial \ln \left(\tau_{w}\right)}=\frac{\tau_{w} \partial\left(\frac{8 v}{d}\right)}{\frac{8 v}{d} \partial\left(\tau_{w}\right)}$

Equation (40) shows that if $\ln \left(\tau_{w}\right)$ vs. $\ln \left(\frac{8 v}{d}\right)$ is plotted the relation between wall shear stress and Newtonian shear rate can be obtained as following,

$\tau_{w}=K^{\prime}\left(\frac{8 v}{d}\right)^{N}$ 
where $K^{\prime}$ is the intercept of $\tau_{\mathrm{w}}$ axis and $\mathrm{N}$ is the slope of a particular $\ln \left(\frac{8 v}{d}\right)$ value. Equation (42) can be used as a general rheological definition of a fluid.

\subsubsection{General Flow Equation of Flow through Circular Pipe}

General flow equation of flow through circular pipe can be obtained after inserting Equation(38) into Equation(36). Hence general laminar flow equation for circular pipe is obtained.

$$
\frac{8 v}{d}=\frac{4}{\tau_{w}^{3}} \int_{0}^{\tau_{w}} \tau^{2} f(\tau) \mathrm{d} \tau .
$$

\subsubsection{General Equation Parameters of Power Fluids}

For a power law fluid shear stress shear rate relation was defined as

$$
\tau=K(f(\tau))^{n},
$$

and

$$
f(\tau)=\left(\frac{\tau}{\mathrm{K}}\right)^{1 / n}
$$

Inserting Equation(45) into Equation(43) and after integration,

$$
\frac{8 v}{d}=\frac{\left(\frac{1}{K}\right)^{1 / n} n \tau_{\mathrm{w}}{ }^{1 / n}}{\frac{1}{4}+\frac{3}{4} n}
$$

Equation(46) can be substituted into the definition of $1 / \mathrm{N}$ and as a result for power law fluids,

$$
N=n .
$$


In order to obtain $K^{\prime}$, Equations (46) and (47) must be substituted into Equation (42). Therefore,

$\tau_{w}=K^{\prime}\left(\frac{\left(\frac{1}{K}\right)^{1 / n} n \tau_{w}^{1 / n}}{\frac{1}{4}+\frac{3}{4} n}\right)^{N}$,

and solving for $K^{\prime}$,

$$
K^{\prime}=K\left(\frac{3 n+1}{4 n}\right)^{n} .
$$

\subsubsection{General Equation Parameters of Bingham Fluids}

A similar procedure must be applied to obtain the general equation parameters of Bingham type fluids analytically. But for this type of fluid, a certain amount of shear stress must be applied to initiate flow. For Bingham plastic fluids shear stress and shear rate equation is

$$
\tau=\tau_{\mathrm{y}}+\mu_{\mathrm{p}} f(\tau)
$$

and

$$
f(\tau)=\frac{\tau-\tau_{\mathrm{y}}}{\mu_{\mathrm{p}}}
$$

Inserting Equation(51) into Equation(43) and integration yields

$$
\frac{8 v}{d}=\frac{\frac{3}{4}\left(\tau_{\mathrm{w}}-\tau_{\mathrm{y}}\right)+\frac{1}{4} \tau_{\mathrm{y}}\left(\left(\frac{\tau_{\mathrm{y}}}{\tau_{\mathrm{w}}}\right)^{3}-1\right)}{\frac{3}{4} \mu_{p}} .
$$


With the equation defining the parameter $1 / \mathrm{N}$ the following equation can be obtained;

$N=\frac{\frac{\tau_{\mathrm{w}}{ }^{3}\left(\tau_{\mathrm{w}}-\tau_{\mathrm{y}}\right)}{\tau_{\mathrm{w}}{ }^{4}-\tau_{\mathrm{y}}{ }^{4}}-\frac{1}{4}}{\frac{3}{4}}$

Substituting the Equations (52) and (53) into Equation(42) and solving for $K^{\prime}$ yields;

$K^{\prime}=\tau_{w}\left(\frac{\frac{3}{4}\left(\tau_{w}-\tau_{y}\right)+\frac{1}{4} \tau_{y}\left(\left(\frac{\tau_{y}}{\tau_{w}}\right)^{3}-1\right)}{\frac{3}{4} \mu_{p}}\right)^{-\left(\frac{\frac{\tau_{w}{ }^{3}\left(\tau_{w}-\tau_{y}\right)}{\tau_{w}{ }^{4}-\tau_{y}{ }^{4}-\frac{1}{4}}}{\frac{3}{4}}\right)}$

Hence an iterative solution procedure is required to obtain the value of $K^{\prime}$ for Bingham type fluids.

\subsubsection{Generalized Reynolds Number}

The generalized Reynolds number equation is derived with the following procedure [46]. Viscosity defined as the following equation,

$$
\mu=\frac{\tau_{w}}{\left(\frac{8 v}{d}\right)}
$$

This can be substituted into Equation(32) hence,

$$
N_{\mathrm{Re}}=\frac{8 \rho v^{2}}{\tau_{w}} .
$$

So the Reynolds number is expressed in terms of wall shear stress. Then substituting general rheological definition, Equation(42), into above equation [46], 
$N_{\mathrm{Re}_{G}}=\frac{8^{1-N} \rho v^{2-N} d^{N}}{K^{\prime}}$

As a result Equation(57) is defined as generalized Reynolds number. After obtaining the $\mathrm{N}$ and $K^{\prime}$ values for any rheological model for circular pipe flow, this equation can be used to determine the flow regime and calculate the friction factor for pressure drop estimation.

Flow regime is estimated with the critical Reynolds number,

$N_{\operatorname{Re}_{c}}=3470-1370 N$

And for laminar flow friction factor generalized Reynolds number relation is [46];

$f_{f}=\frac{16}{N_{\mathrm{Re}_{G}}}$

where $f_{f}$ is the fanning friction factor. For turbulent flow, Dodge-Metzner [47] equation can be used which is

$\frac{1}{\sqrt{f_{f}}}=\frac{4}{N^{0.75}} \log \left(N_{\operatorname{Re}_{G}} f_{f}^{1-\frac{N}{2}}\right)-\frac{0.395}{N^{1.2}}$.

The disadvantage of this equation is its implicit form. Dodge and Metzner [47] stated that although Blasius equation is an inferior form of above equation, it can be used for non-Newtonian fluids within a range of Reynolds number 3,000 to 100,000 for an approximation of friction factor [47]. Blasius equation is;

$f_{f}=0.0791 \frac{1}{N_{\mathrm{Re}}{ }^{1 / 4}}$.

After obtaining the value of fanning friction factor, pressure drop can be estimated with Fanning Equation(21). 


\subsection{Viscosity}

Laminar flow behavior of all fluids within a rotational viscometer of the Fann VG Meter type is [48],

$$
\omega_{c}=\frac{k}{2} \int_{\tau_{b} / \beta^{2}}^{\tau_{b}} \tau^{-1} \theta(\tau) d \tau
$$

Where,

$$
\begin{aligned}
& \beta=r_{c} / r_{b} \\
& r_{b}=\text { radius of inner bob } \\
& r_{c}=\text { radius of outer bob } \\
& \tau_{b}=T / 2 \pi L r_{b}^{2} \text { shear stress experienced by fluid in contact with bob } \\
& L=\text { effective length of bob } \\
& T=\text { Torque transmitted to bob } \\
& \omega_{c}=\text { angular velocity of outer cylinder } \\
& k \theta(\tau)=\frac{d v_{r}}{d r}, \text { shear stress - shear rate behavior of fluid }
\end{aligned}
$$

After substituting shear rate shear stress relation for power law fluids, which is

$k \theta(\tau)=\left(\frac{1}{K}\right)^{\frac{1}{n}} \tau^{1 / n}$,

into Equation(62) and performing the necessary calculations, shear stress at the bob can be obtained with the following equation

$$
\tau_{b}=K \gamma^{n}\left(\frac{2 \omega_{c} \beta^{2}}{\beta^{2}-1}\right)^{n}
$$

Where

$$
\gamma=\left(\frac{\beta^{2 / n}}{n \beta^{2}}\right)\left(\frac{\beta^{2}-1}{\beta^{2 / n}-1}\right)
$$

After taking the logarithms of each side of the Equation(64),

$$
\log \tau_{b}=\log \left(K \gamma^{n}\right)+n \log \left(\frac{2 \omega_{c} \beta^{2}}{\beta^{2}-1}\right)
$$


Hence, a plot of $\left(\frac{2 \omega_{c} \beta^{2}}{\beta^{2}-1}\right)$ vs. $\tau_{\mathrm{b}}$ will result in a straight line with the slope $n$. Also the intercept on the $\tau_{b}$ axis will be $K_{v}{ }^{\prime}$.

Table 4.3.1 Standard rotor-bob combination and speed settings for Model 35 Fann V-G Meter [48]

\begin{tabular}{|c|c|}
\hline $\begin{array}{c}\text { Cylinder Speed } \\
\boldsymbol{\omega}_{\mathbf{c}}, \mathbf{r p m}\end{array}$ & $\left(\frac{2 \omega_{c} \beta^{2}}{\beta^{2}-1}\right), \mathbf{s e c}^{-1}$ \\
\hline 600 & 1022 \\
\hline 300 & 511 \\
\hline 200 & 340 \\
\hline 100 & 170 \\
\hline 6 & 10.2 \\
\hline 3 & 5.1 \\
\hline
\end{tabular}

With the two operating speeds of 300 and $600 \mathrm{rpm}, n$ and $K_{\mathrm{v}}{ }^{\prime}$ can be obtained simply with the below formulas [48],

$n=3.32 \cdot \log \left(\theta_{600} / \theta_{300}\right)$

and

$K_{v}^{\prime}=\frac{N(0.01066) \theta_{300}}{511^{n}}$

Where $\mathrm{N}=1$ for standard torsion spring equipped instrument. Also the unit of $\mathrm{K}_{\mathrm{v}}$ ' for the Equation(68) is in lbf-s/ $\mathrm{ft}^{2}$. Plastic viscosity (cp) of a Bingham fluid can be calculated as follows;

$\mu_{p}=\theta_{600}-\theta_{300}$

Yield stress (lbf-s/ft ${ }^{2}$ ) can be calculated as

$\tau_{y}=\mu_{p}-\theta_{300}$ 
The effective viscosity of a Bingham fluid can be obtained by the following method [48]. Substituting Equations (51) and (18) into Equation(43) then integrating and solving for $\Delta \mathrm{P}$ yields,

$$
\Delta P=\frac{32 \mu_{p} L v}{d^{2}}+\frac{16 \tau_{y} L}{3 d} .
$$

Hagen-Poiseuille's equation is;

$$
\Delta P=\frac{32 \mu L v}{d^{2}}
$$

Equating Equation(71) and Equation(72) and solving for the effective viscosity yields;

$\mu_{e}=\mu_{p}+\frac{6.65 \cdot \tau_{y} \cdot d}{v} \quad$ (English Units)

Effective viscosity of Power law fluids can also be evaluated with the same manner and the below equation can be obtained [48].

$\mu_{e}=\left(\frac{d}{v}\right)^{(1-n)}\left(\frac{K}{96}\right)\left(\frac{\frac{3 n+1}{n}}{0.0416 \cdot n}\right)^{n} \quad$ (English Units)

\subsection{Seyer and Metzner Correlation}

Seyer and Metzner [17] deduced an empirical relationship of friction factor and Reynolds number based on the Townsend-Bakewell model. This model shows that viscoelastic fluid properties result in significant drag reduction at turbulent shear flows. Seyer and Metzner used ET-597 (High molecular weight Polyacrylamide) 
during their experiments. The main equation obtained empirically for the estimation of friction factor of drag reducing systems is given below:

$\sqrt{\frac{2}{f}}=A\left(1-\xi_{\mathrm{l}}\right)^{2} \ln N_{\mathrm{Re}} \sqrt{f}+\left(1-\xi_{\mathrm{l}}\right)^{2}\left[B_{(\mathrm{I})}-A \ln 2 \sqrt{2}\right]-G$

In this equation $\mathrm{G}$ was approximated as 3.00 for design purposes. The validity of the value chosen for $\mathrm{G}$ was verified by comparing centerline velocities obtained from this value of $\mathrm{G}$ with experimental measurements. A is stated to be taken as 2.46 for either Newtonian or Non-Newtonian fluids. Hence the equation can be rewritten as,

$$
\sqrt{\frac{2}{f}}=2.46\left(1-\xi_{l}\right)^{2} \ln N_{\mathrm{Re}} \sqrt{f}+\left(1-\xi_{l}\right)^{2}\left[B_{(\mathrm{I})}-2.46 \ln 2 \sqrt{2}\right]-3.00
$$

Where, $\xi_{l}$ is the value of $\xi$ defined by $\mathrm{y}_{1}^{+}$where $\left(y^{+}=\frac{u^{*} y}{v}\right)$ and $\left(\xi=\frac{y}{R}\right) \cdot y_{l}^{+}$is the value of $y^{+}$defined by the intersection of linear and logarithmic velocity profiles. $B_{(\mathrm{I})}$ is defined with the equation below,

$$
B_{(\mathrm{T})}=y_{l}^{+}-A \ln y_{l}^{+}
$$

Dimensionless time ratio ('I ) is defined as,

$$
\mathrm{I}=\frac{\theta\left(u^{*}\right)^{2}}{v} \text {. }
$$

After obtaining the dimensionless time ratio, the value of B can be obtained from the Figure. 2 of [17]. $\theta$ is the relaxation time of the polymer molecules in the prepared solution and can be obtained with the equation below according to the Zimm theory [23],

$$
\theta_{k}=\frac{M_{v} \cdot \frac{n_{s p}}{c} \cdot \mu_{o}}{0.586 \cdot R \cdot T \cdot \lambda_{k}}
$$

And $n_{s p}$ is the specific viscosity and can be obtained as, 
$n_{s p}=\frac{\mu_{\mathrm{s}}-\mu_{o}}{\mu_{o}}$,

$\mu_{\mathrm{s}}$ is the solution viscosity and $\mu_{o}$ is the solvent viscosity. And $M_{v}$ is viscosity average molecular weight, $\mathrm{c}$ is the concentration, $\mathrm{R}$ is gas constant, $\mathrm{T}$ is absolute temperature and $\lambda_{k}$ is the eigenvalue corresponding to the $\mathrm{k}^{\text {th }}$ mode of relaxation. First mode of relaxation should be used here. Also friction velocity can be obtained with the equation below,

$u^{*}=\sqrt{\frac{\tau_{w}}{\rho}}$.

\subsection{Shaver and Merrill Correlation}

High molecular weight linear polymers, sodium carboxymethylcellulose, ammonium alginate, polyisobutylene and carboxypolymethylene were used to obtain a correlation for the friction factor at pseudoplastic turbulent flow [2]. Power law shear stress shear rate relation was used to evaluate the experimental data.

$$
\tau=k\left(\frac{d u}{d y}\right)^{n}
$$

And the following equations were utilized to obtain fanning friction factor and Reynolds number. All the experimental data are correlated empirically with the following equations;

$$
f=\left(\frac{0.079}{n^{5} \cdot N_{\mathrm{Re}}^{\gamma}}\right)
$$

where

$$
\gamma=\frac{2.63}{(10.5)^{n}}
$$


This correlation reduces to the Blasius equation in the case of $n=1.00$. It as also stated that this correlation can not be used with fluids having an $\mathrm{n}$ value less than about 0.4 since the predicted friction factor values will be less than in laminar flow. And it is noted that in solutions of random coiling, non-associating, high molecular weight polymers sufficiently dilute to avoid gel structure and gross elasticity, the value of $\mathrm{n}$ has never been found lower than 0.5 according to Shaver and Merrill [2]. 


\section{CHAPTER 5}

\section{EXPERIMENTAL}

\subsection{Flow Loop}

The drag reduction experiments were performed with a flow loop which consists of a plastic tank, a centrifuge pump, a rotameter and a valve to adjust the flow rate of the system. Test section of the system is $100.5 \mathrm{~cm}$ long corrosion resistant steel pipe and the pressure drop at this section was measured with a differential pressure gauge. Inner diameter of the tube at the test section is $0.42 \mathrm{in.}$ In order to decrease the end effects and to maintain fully developed flow the length of the upstream and downstream of the test section should be higher than a certain value. This value is calculated with the formulas below $[49,50]$.

$$
\begin{aligned}
& L_{\text {upstream }}=50 \cdot(D) \\
& L_{\text {downstream }}=4.4 \cdot\left(N_{\mathrm{Re}}\right)^{1 / 6} \cdot(D)
\end{aligned}
$$

For our case $L_{\text {upstream }}$ must be longer than $53.34 \mathrm{~cm}$ and $L_{\text {downstream }}$ must be longer than $27 \mathrm{~cm}$. Those values for our flow loop are as following;

$L_{\text {upstream }}=3.70 \mathrm{~m} \quad$ and $\quad L_{\text {downstream }}=1.70 \mathrm{~m}$.

The volume of the tank used was $30 \mathrm{~L}$ (7.93 gal) and the solution was mixed at this tank to obtain homogenous solution before the drag reduction experiments. The centrifugal pump gives maximum of $5.5 \mathrm{gpm}$ flow rate for the flow loop used. 


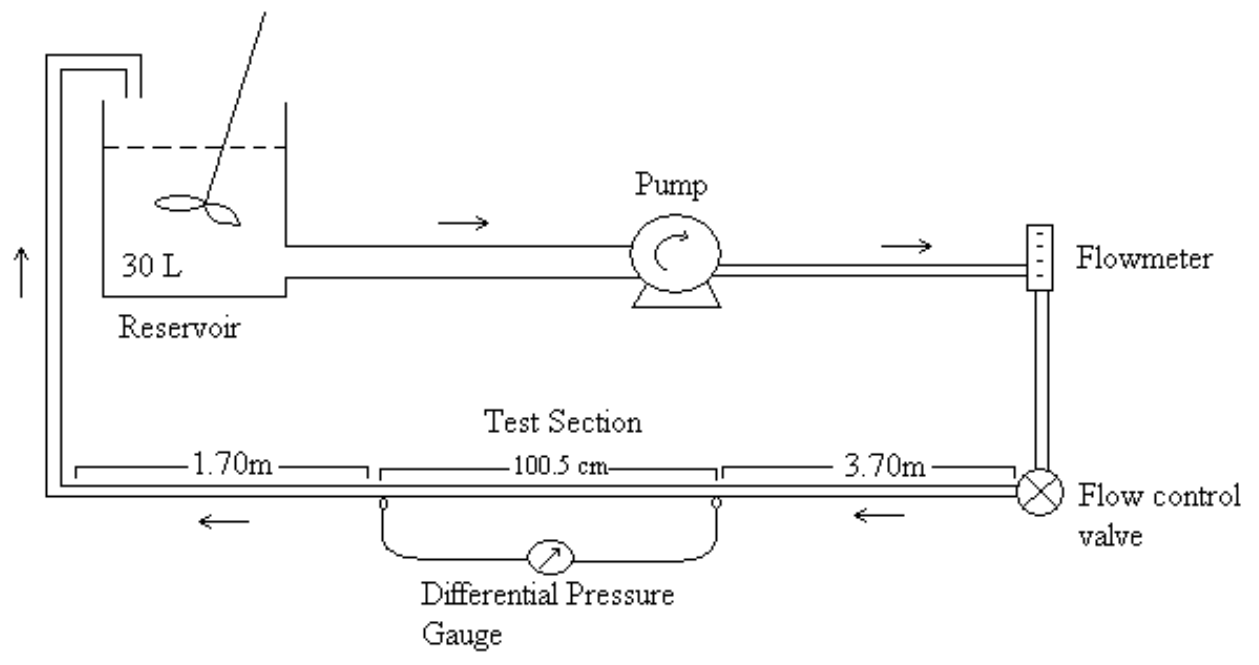

Figure 5.1 - Experimental Set-up

The polymer solutions were prepared with EZ-Mud which is a liquid polymer emulsion containing Partially Hydrolyzed Polyacrylamide / Polyacrylate (PHPA) copolymer. EZ-Mud is generally used as a borehole stabilizer against swelling and sloughing problems encountered during the drilling. EZ-Mud was chosen because of its high molecular weight makes it easier to observe and record drag reduction data, it mixes easily with fresh water. Besides, even though its drag reduction effect is known, there is not sufficient theoretical information about the effects of concentration or flow properties on this phenomenon. 
Table 5.1 - Physical properties of EZ-Mud (Halliburton)

\begin{tabular}{|c|c|}
\hline Molecular Weight & $(4-6) \times 10^{6}$ \\
\hline Appearance & Thick, opaque white liquid \\
\hline Density & $8.5 \mathrm{lb} / \mathrm{gal}\left(1.02 \mathrm{~g} / \mathrm{cm}^{3}\right)$ \\
\hline $\mathrm{pH}$ (1 quart per 100 gallons water) & 8.5 \\
\hline Flash point, $\mathrm{PMCC}{ }^{\circ} \mathrm{F},{ }^{\circ} \mathrm{C}$ & $>200(>93.3)$ \\
\hline Thermal stability, ${ }^{\circ} \mathrm{F},{ }^{\circ} \mathrm{C}$ & $250(121)$ \\
\hline
\end{tabular}

Tap water was used to prepare the solutions for the desired concentrations. First, water was circulated to check and clean the flow loop. Later, the elastic pipes of differential pressure gauge were flushed with water to remove any air bubbles. Then water flow experiments were performed to check differential pressure. 30L water was circulated at 7 different flow rates hence 5 sets of water experiment data were obtained.

Polymer solutions were obtained by adding the proper amount of EZ-Mud to the $30 \mathrm{~L}$ tap water in the reservoir. After the addition of the EZ-Mud, solution was mixed for 10 minutes to obtain a homogenous system. This system was circulated at different flow rates by adjusting the flow control valve. The flow loop was flushed with water after each drag reduction run. Besides, a new solution was prepared after each run, again by adding proper amount of EZ-Mud to $30 \mathrm{~L}$ water and later applying the same procedure.

As a result, differential pressure data for 8 different concentrations at 8 different flow rates were recorded. Flow rates were increased from $1.5 \mathrm{gpm}$ to $5.0 \mathrm{gpm}$ with $0.5 \mathrm{gpm}$ increments and then flow rate decreased to $1.5 \mathrm{gpm}$ by the same incremental amount. The concentrations (v/v) were 0.000313, 0.000625, 0.000938, $0.00125,0.00156,0.00188,0.00219$ and 0.00250 . 
Before beginning the drag reduction experiments the rotameter was checked if it is working properly. A bucket $(1 \mathrm{~L})$ was filled and the time needed to fill the bucket was recorded and the flow rate was calculated. Calculated flow rates are compared with the flow meter readings on the rotameter. This procedure is repeated with "water" and "two different polymer concentrations". The flow meter readings were accurate.

\subsection{Rheological Measurements}

Rheological measurements of the solutions were obtained with Fann Viscometer (Model 35SA, Fann Instrument Company). The same concentrations used for the flow tests were obtained by adding EZ-Mud to the sample cup of the viscometer. The volume of the sample cup is $350 \mathrm{ml}$. Before the measurements with the viscometer, solutions were mixed with a Fann Multimixer for 5 minutes. After mixing the solutions, dial readings at 300 and $600 \mathrm{rpm}$ were recorded, for the concentrations listed above, at room temperature. 


\section{CHAPTER 6}

\section{RESULTS AND DISCUSSION}

In this chapter, the results of the experimental studies are presented. Besides, obtained graphs and other data are discussed and a correlation was proposed for the pressure drop estimation of EZ-mud. This correlation then is compared with other similar correlation from the literature.

\subsection{Water Experiments}

Five set of data were obtained during the water experiments. These data were plotted with the theoretical data at the Figure 6.1.1. Flow rate vs. differential pressure was plotted for those five set of data and it can be seen that theoretical curve fits well with the obtained experimental data. Hence it is clear that the experiments are repeatable based on the comparison with the theoretical curve. Reynolds number for each flow rate was calculated with Equation(32). Then $f_{f}$ was obtained with Equation(61) and frictional pressure loss was calculated with Equation(21). As a result the theoretical curve is obtained. 


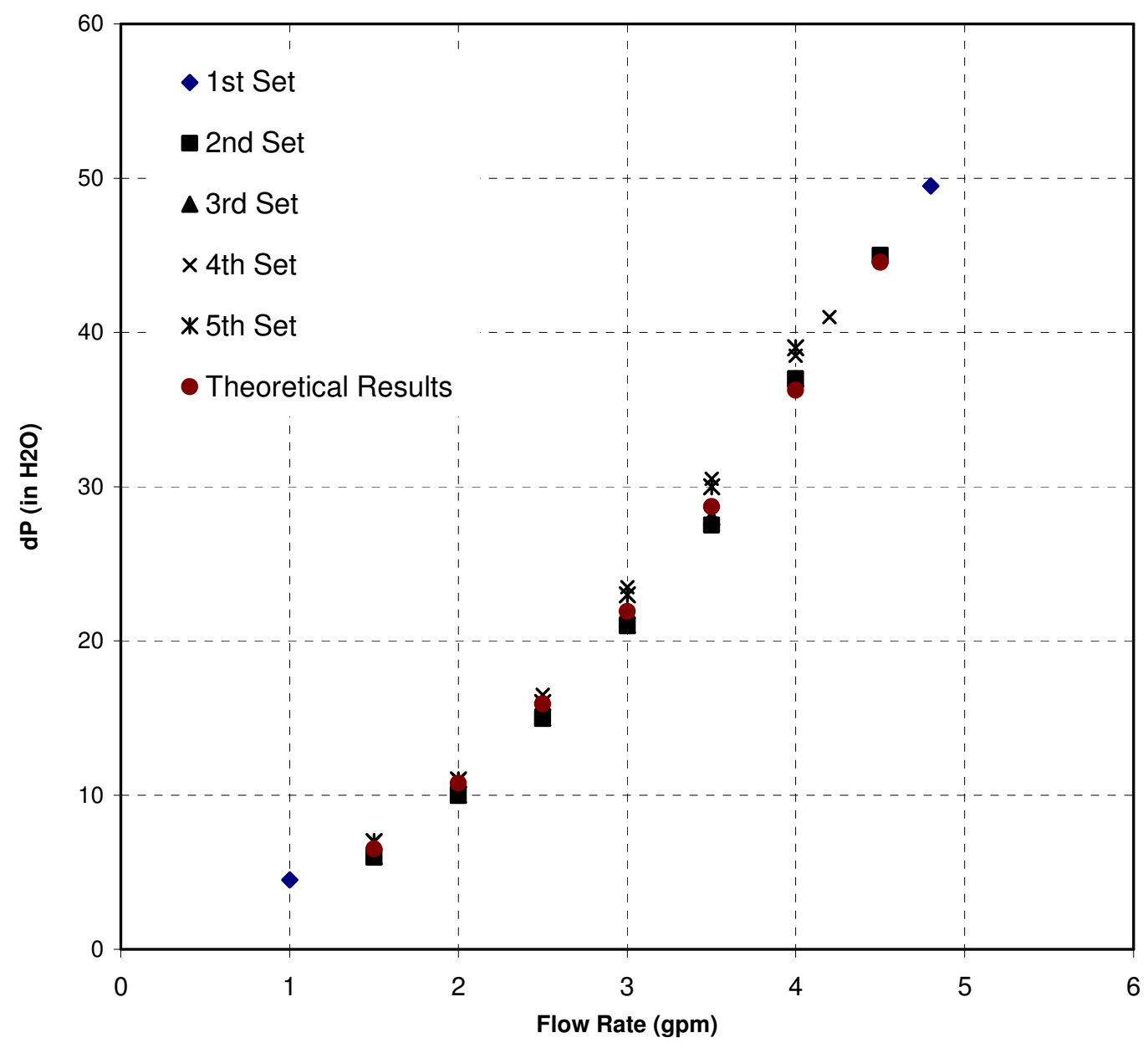

Figure 6.1.1 Water Experiment Results

Deviation from the theoretical curve at low flow rates is a result of low accuracy of differential pressure gauge at these low pressure values. Also at these flow rates flow regime is close to transition flow.

As it is seen from the Table 6.1.1, absolute percent errors for flow tests are below $8 \%$. Only at low flow rates, higher percent error values are observed for all sets because the accuracy of the differential pressure gauge used was not sufficient below 10 (in. water). 
Table 6.1.1 Absolute Percent Error for Water Data Sets

\begin{tabular}{|c|c|c|c|c|c|}
\hline $\begin{array}{c}\text { Flow Rate } \\
\text { (gpm) }\end{array}$ & Set-1 & Set-2 & Set-3 & Set-4 & Set-5 \\
\hline $\mathbf{1 . 5}$ & 7.91 & 7.91 & 7.91 & 7.44 & 7.44 \\
\hline $\mathbf{2 . 0}$ & 2.59 & 7.22 & 7.22 & 2.05 & 2.05 \\
\hline $\mathbf{2 . 5}$ & 5.83 & 5.83 & 5.83 & 3.59 & 0.45 \\
\hline $\mathbf{3 . 0}$ & 1.89 & 4.17 & 4.17 & 7.24 & 4.95 \\
\hline $\mathbf{3 . 5}$ & 4.18 & 4.18 & 2.44 & 6.27 & 4.53 \\
\hline $\mathbf{4 . 0}$ & 0.68 & 2.05 & 2.05 & 6.19 & 7.57 \\
\hline $\mathbf{4 . 5}$ & 1.00 & 1.00 & 1.00 & 1.00 & 1.00 \\
\hline
\end{tabular}

\subsection{Mud Properties}

Results of the rheological measurements of EZ-Mud water systems at different concentrations were presented at this section. Different concentrations of EZ-Mud were prepared at the laboratory and Figure 6.2.1 was obtained. As it is observed from the Figure 6.2.1, solutions show Non-Newtonian behavior and the value of ' $\mathrm{n}$ ' decreases with increasing concentration.

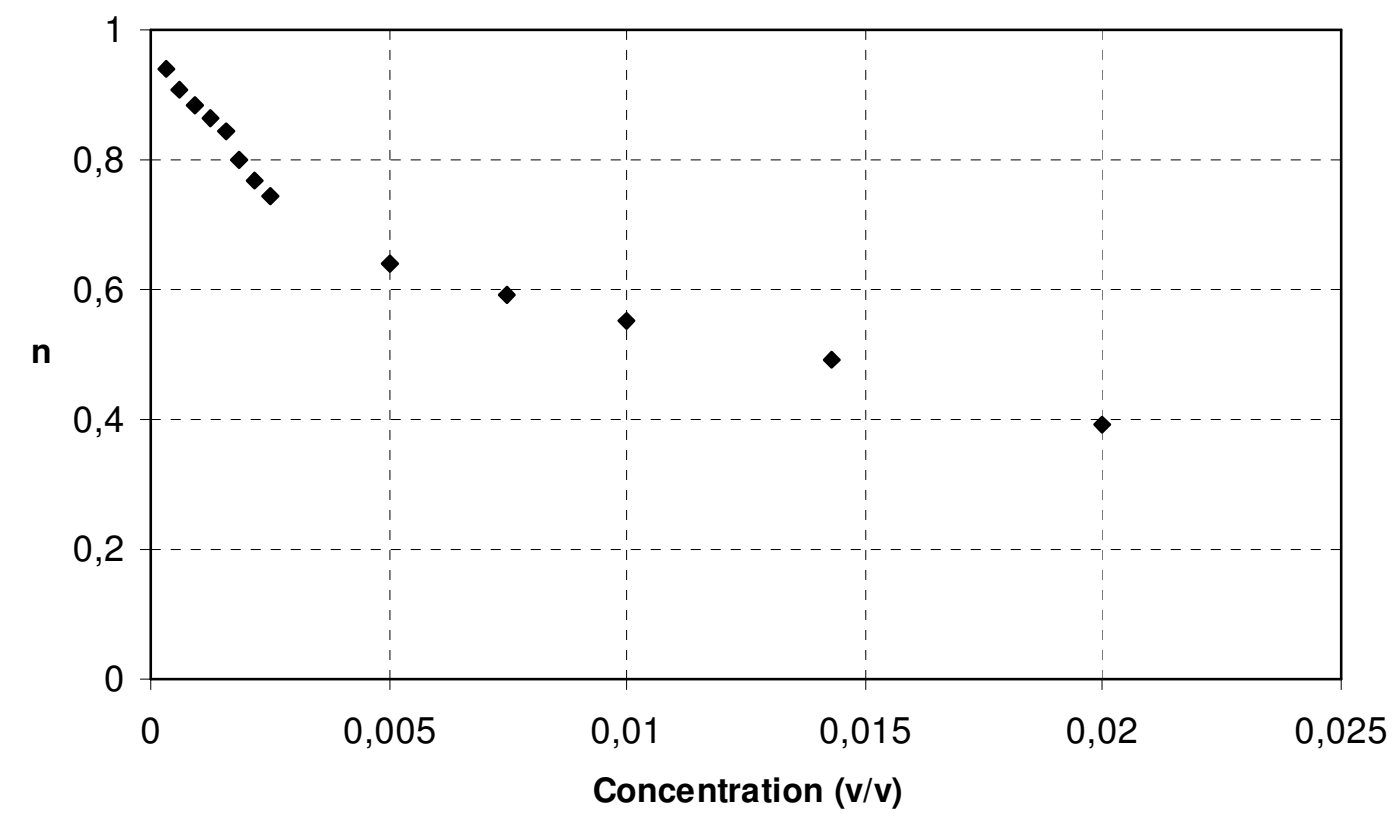

Figure 6.2.1 Concentration vs. ' $n$ ' 
Similarly, the values of $\mathrm{K}$ (consistency index) increases with increasing concentration. The Figure 6.2.2 shows that behavior on Cartesian coordinates. At low concentrations the value of $\mathrm{K}$ changes between 3 and 40 centipoises but after concentration value of 0.0025 it increases exponentially. So by looking only at this graph it can be stated that after concentration exceeds $0.0025(\mathrm{v} / \mathrm{v})$, the solution becomes more and more viscous which may alter its drag reduction properties adversely. K and n obtained by the Equations (67) and (68).

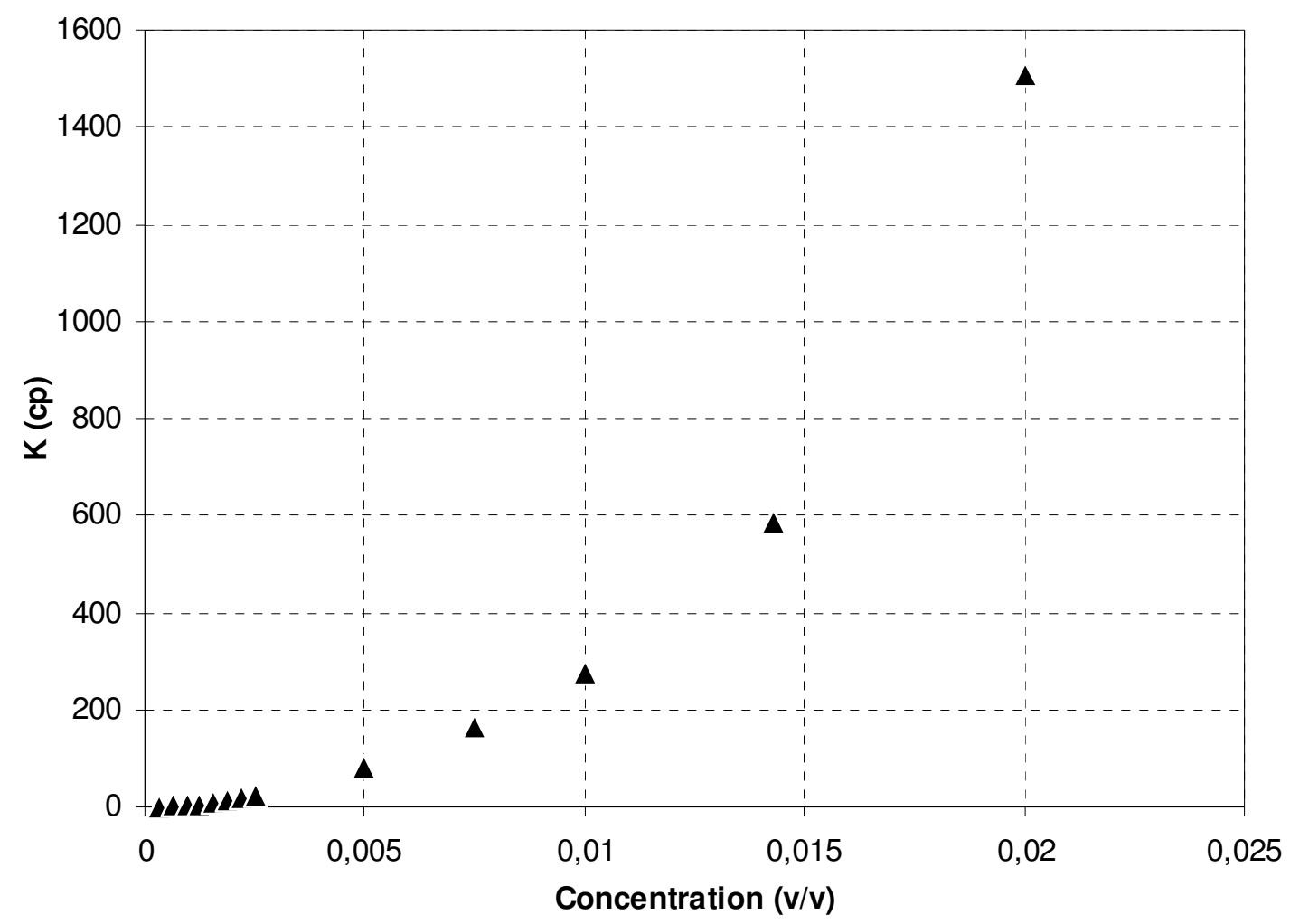

Figure 6.2.2 Concentration vs. K

Rheological parameters for Bingham Plastic as a function of EZ-Mud ${ }^{\mathrm{TM}}$ concentration are presented in Appendix, Table A.2. On the other hand it was not possible to obtain a complete rheological profile of the solutions because of the limitations with the viscometer since it can not give low shear rates. Hence it is not possible to determine accurately whether the solutions are Bingham or Power fluid. Accordingly calculations were performed for both Bingham and Power models. 


\subsection{Drag Reduction Experiments}

Drag reduction experiments for 8 concentrations at 8 flow rates were performed. Results are demonstrated at the following figures. Two sets of frictional pressure drop measurements were recorded.

At the Figure 6.3.1, flow rate vs. differential pressure (in. water) at different concentrations were plotted. Flow rates were changed between $1.5 \mathrm{gpm}$ to 5.0 gpm. The concentrations (v/v) were changed between 0.000313 and 0.002500 . At the Figure 6.3.1 drag reduction can easily be observed. As the concentration increases lower differential pressure was observed at the test section of the flow loop

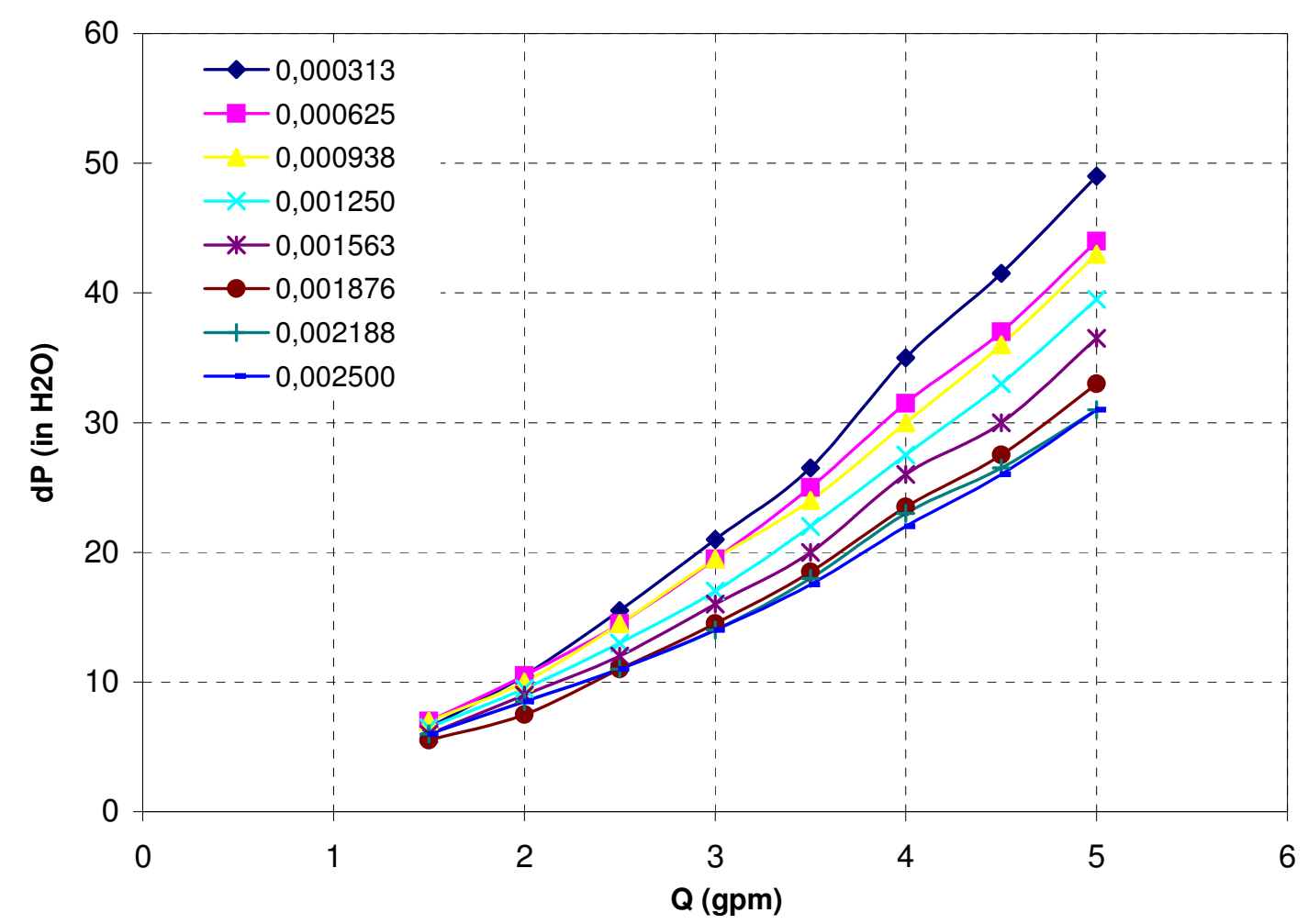

Figure 6.3.1 Flow rate vs. measured $\mathrm{dP}$ at different concentrations

$\left(1^{\text {st }}\right.$ set of data) 
Also, concentration vs. differential pressure was plotted at the Figure 6.3.2. At different flow rates, drag reduction effect of the polymer solution was demonstrated. Drag reduction effect at higher flow rates are more pronounced. Moreover, this plot indicates that increase of concentration after around 0.0020 does not result in further drag reduction. Hence optimum concentration for EZMud for drag reduction is $0.0020(\mathrm{v} / \mathrm{v})$.

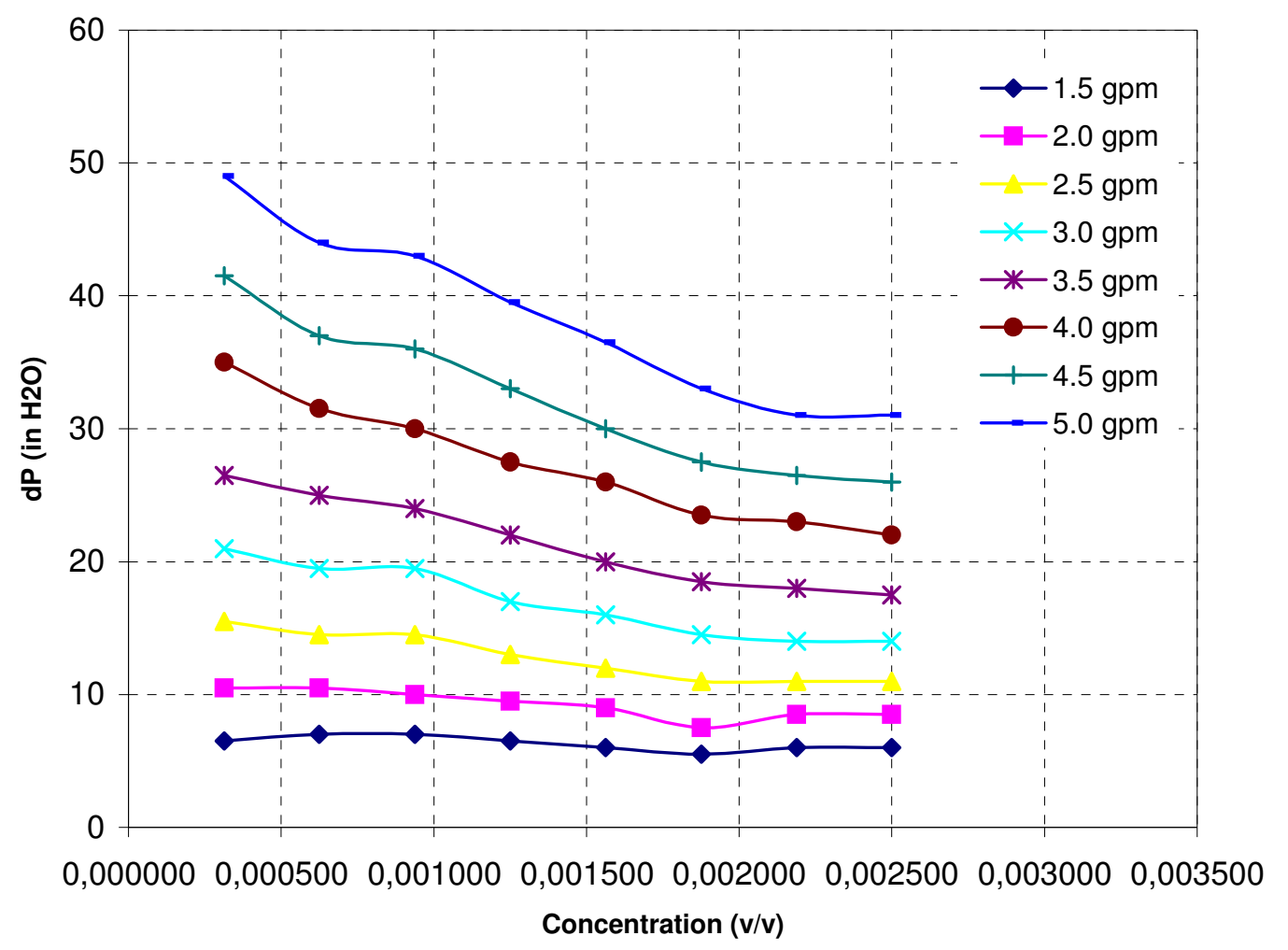

Figure 6.3.2 Concentration vs. Differential Pressure at Different Flow Rates $\left(1^{\text {st }}\right.$ set of data)

Differential pressure was calculated assuming the solution has Bingham fluid rheological properties. Accordingly, effective viscosity was calculated using the Equation(73) and then Reynolds number calculated with this viscosity. Then friction factor and differential pressure was calculated with Equations (61) and (21). At the Figure 6.3.3, measured dP (in. water) vs. calculated dP (in. water) was plotted. 


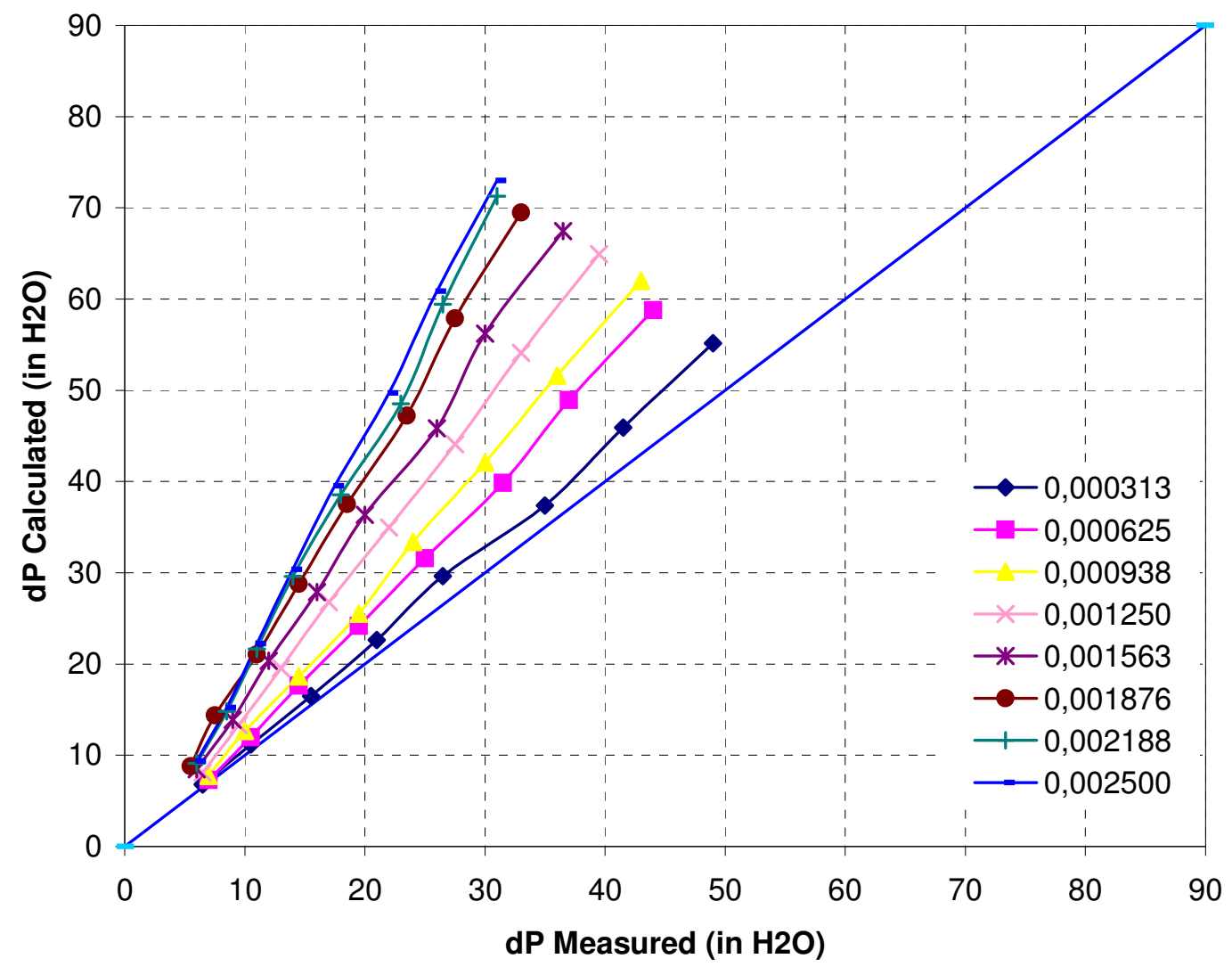

Figure 6.3.3 Measured vs. Calculated Differential Pressure with Bingham Model

Similar calculation was applied to calculate differential pressure expected assuming the solution has power law rheological properties. Then effective viscosity was calculated with Equation(74) and differential pressure values were obtained and plotted for the power law model. Measured and calculated differential pressure values are plotted for Power model in Figure 6.3.4.

As it is observed at the Figures 6.3.3 and Figure 6.3.4, calculated frictional pressure drop values are higher than measured values. This abnormal behavior of EZ-Mud can result in incorrect design calculations. Therefore, a better correlation is required to estimate the pressure drop of EZ-Mud solutions at a reasonable accuracy. 


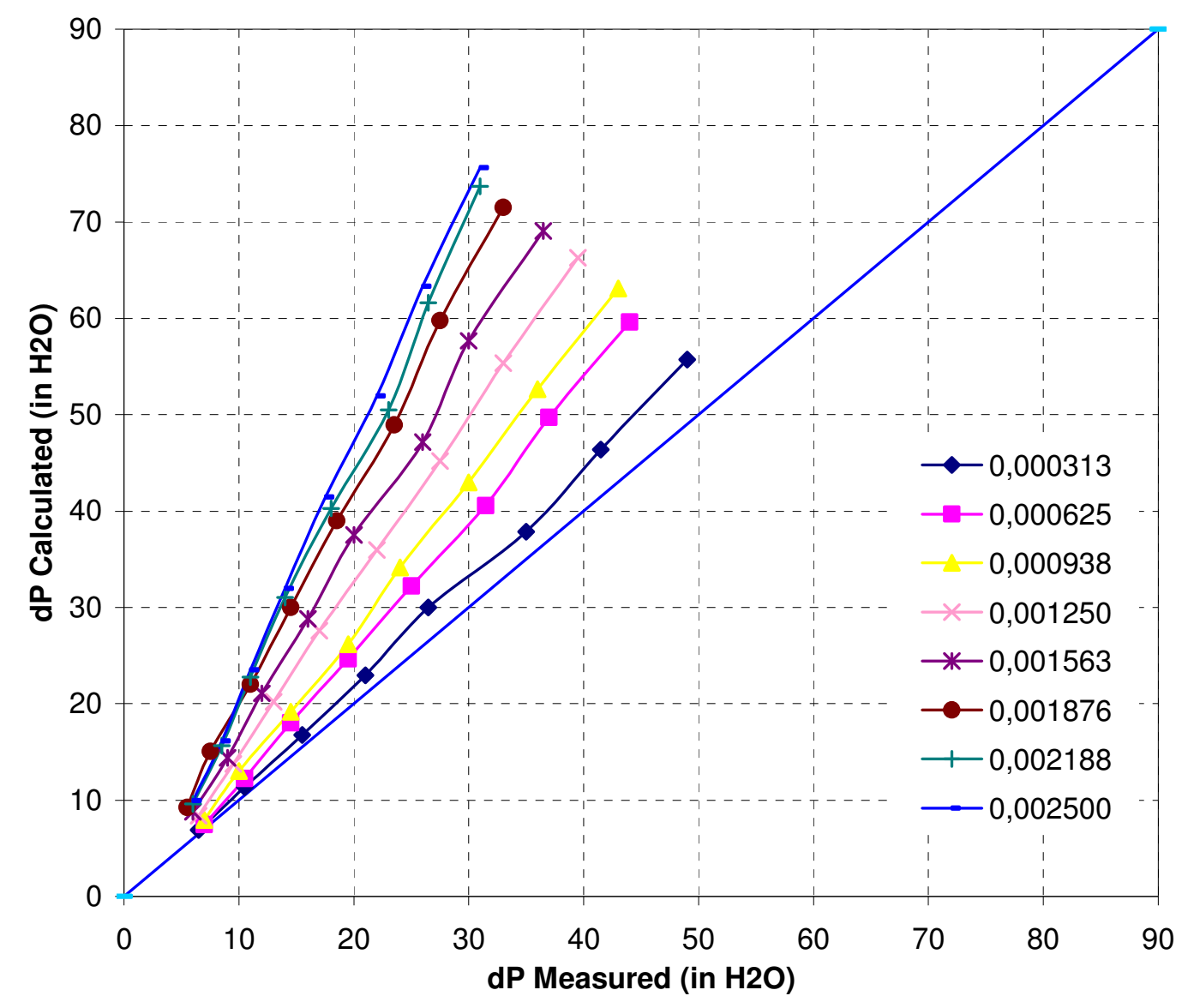

Figure 6.3.4 Measured vs. Calculated Differential Pressure with Power Model

Reynolds number friction factor data were plotted on logarithmic coordinates for the Bingham model at the Figure 6.3.5. Virk's Maximum Drag Reduction curve and Prandtl-Karman curve are also calculated with Equations(5) and (61) and represented to observe the effect of concentration on drag reduction. At the Figure 6.3.5, fanning friction factor decreases with increasing concentration at a constant Reynolds number. 


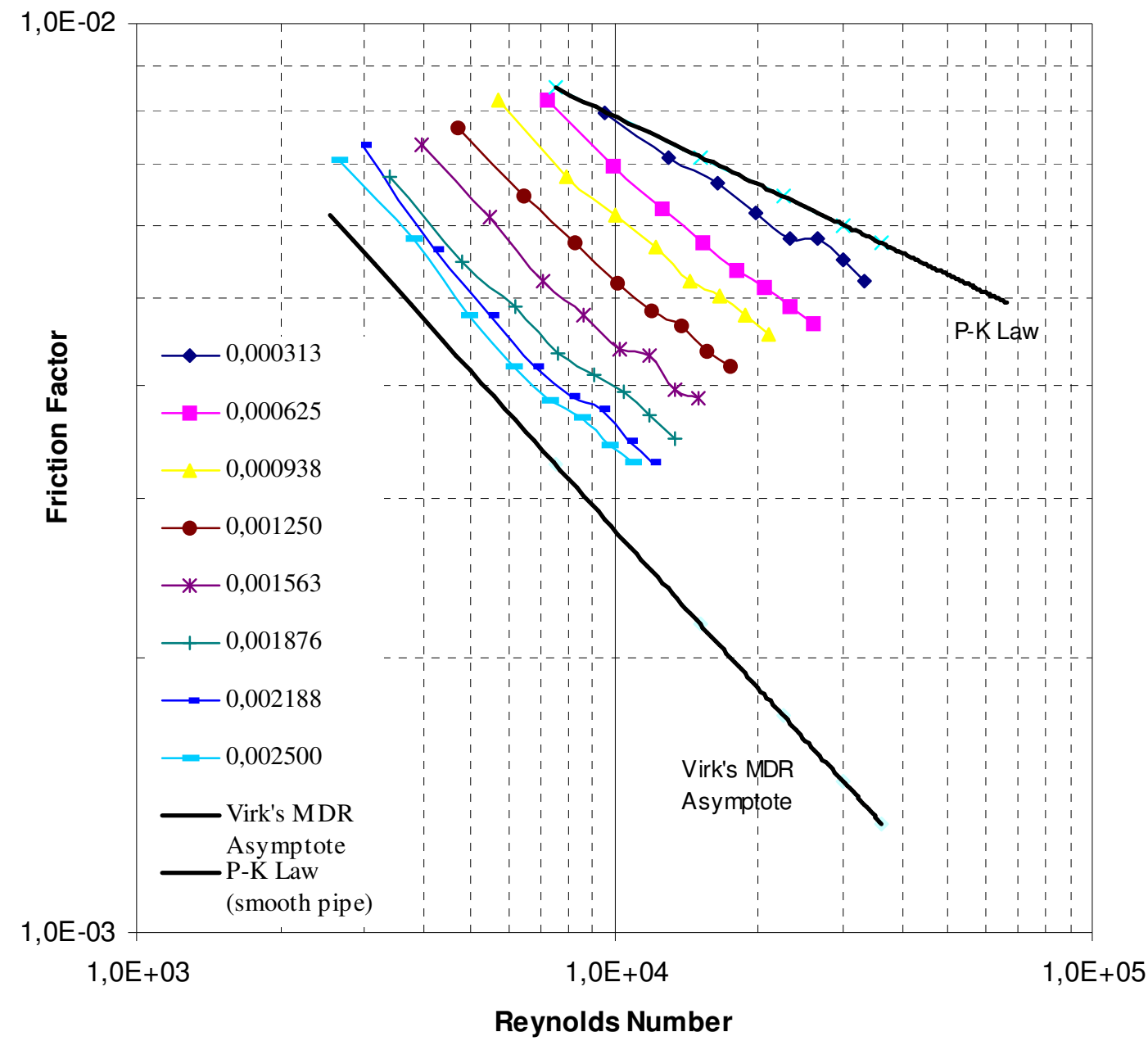

Figure 6.3.5 Reynolds Number vs. Friction Factor Curves for Bingham Model

Power law expression for the friction factor Reynolds number curves were represented on the Figure 6.3.6.Becasue of higher calculated effective viscosity of Power model, friction factor values are lower than Bingham model at the Figure 6.3.6. 


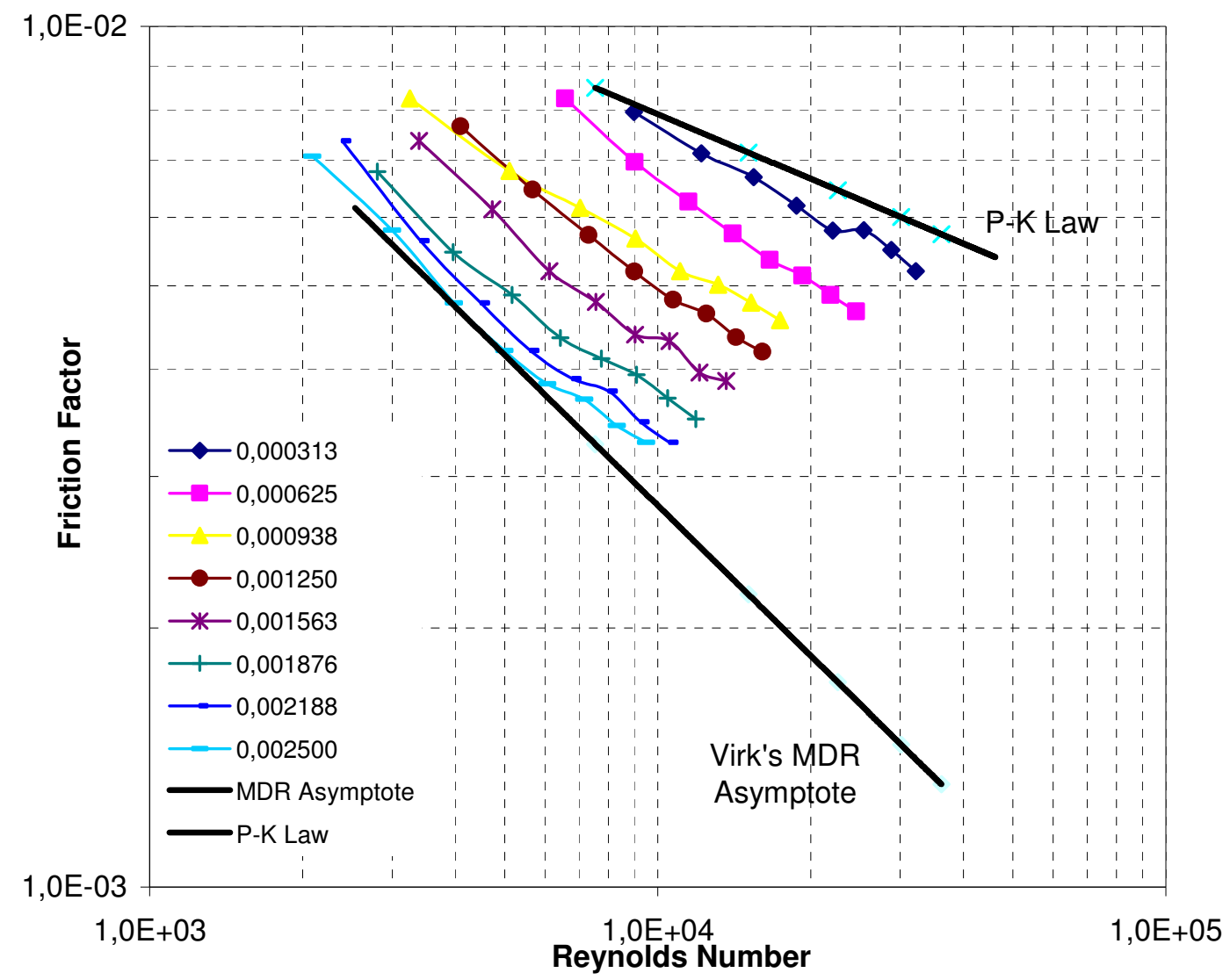

Figure 6.3.6 Reynolds Number vs. Friction Factor Curves for Power Model

Percent drag reduction vs. concentration was plotted on Cartesian coordinates to understand the concentration effect on drag reduction at Figure 6.3.7. After the concentration above 0.0020 , addition of further polymer does not increase drag reduction. Therefore previously assumed concentration of 0.0020 for optimum concentration can still be preserved.

Drag reduction was calculated with the following formula [31],

$\% D R=\frac{\Delta P_{c a l}-\Delta P_{m e}}{\Delta P_{c a l}} \times 100$

Accordingly drag reduction was calculated for both of the fluid models, Bingham and Power Laws. 


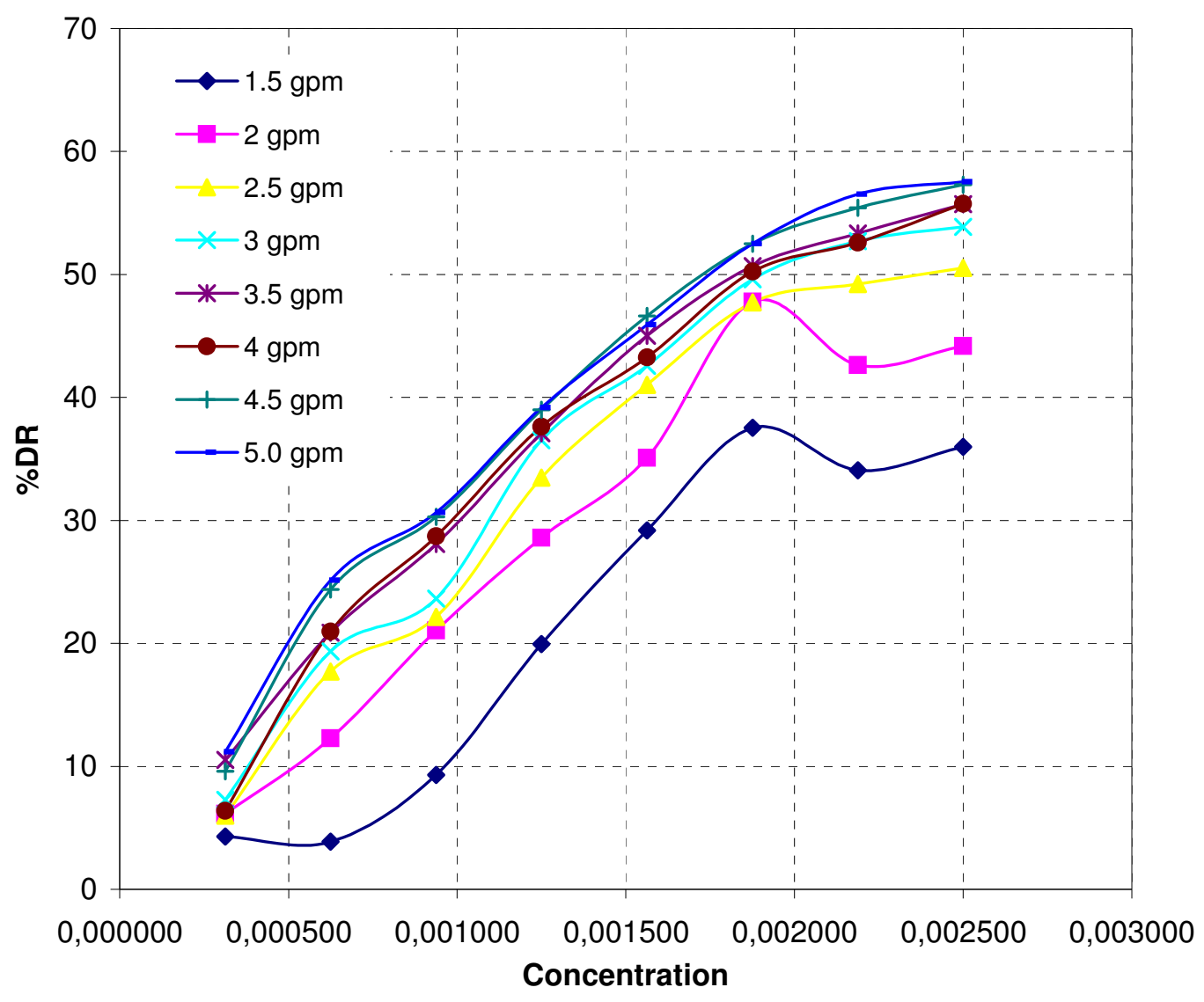

Figure 6.3.7 Concentration vs. Percent Drag Reduction (Bingham $-1^{\text {st }}$ Set of Data)

Higher drag reduction values obtained because of the higher calculated differential pressure for power law model. Maximum drag reduction obtained for Bingham law is $58 \%$ whereas maximum drag reduction obtained for Power law model is 59 $\%$.

Hoyt [31] stated that $80 \%$ drag reduction can be attained with PAM solutions. Obtained drag reduction results are less than that value but considerable drag reduction is obtained for evaluation. 


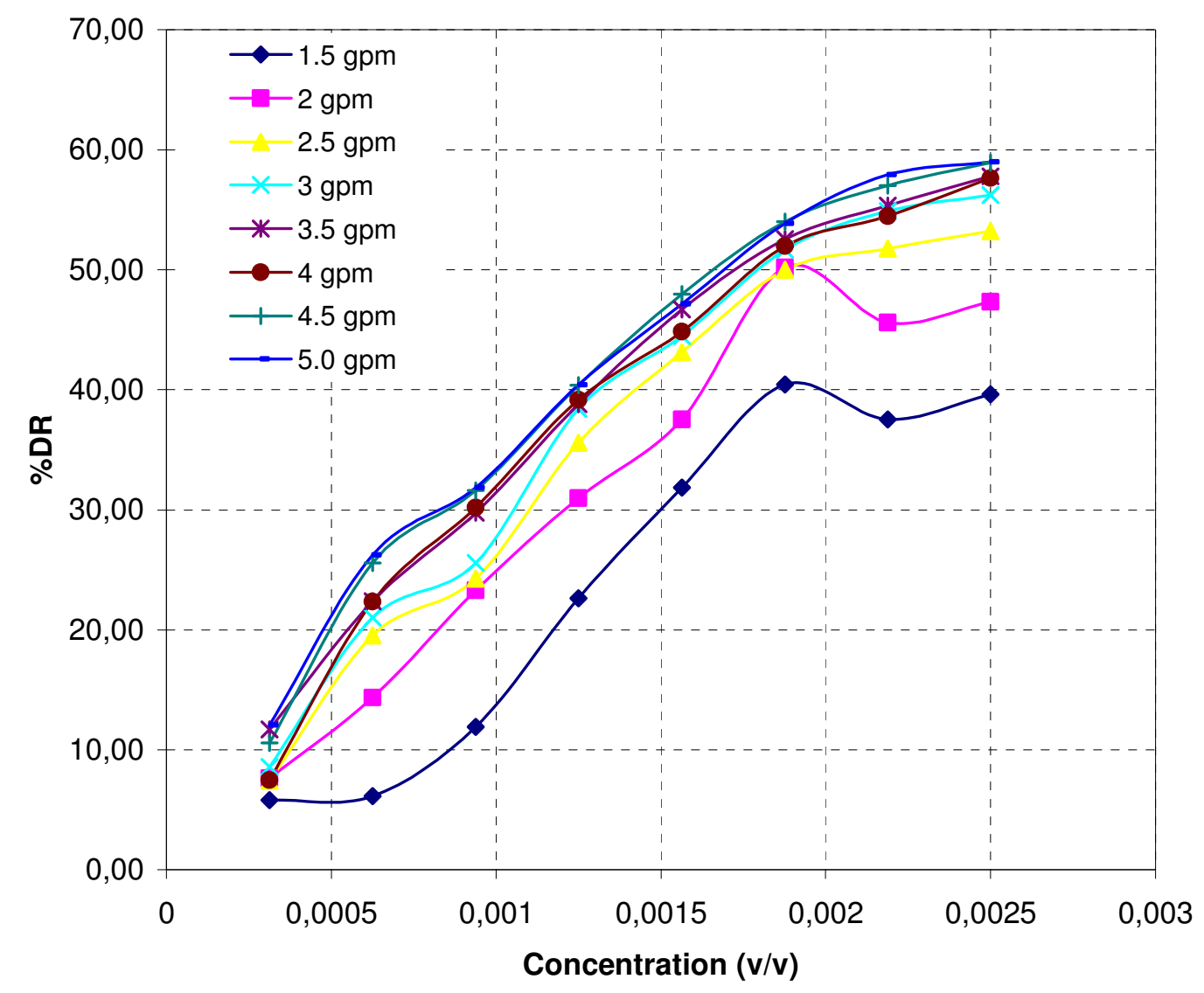

Figure 6.3.8 Concentration vs. Percent Drag Reduction (Power $-1^{\text {st }}$ Set of Data)

A simple correlation was obtained to calculate the fanning friction factor for the solution of EZ-Mud and water to estimate the differential pressure. The correlation obtained is as following:

$$
f_{f}=A \cdot\left(N_{\mathrm{Re}} \cdot c\right)^{B}
$$

Where $\mathrm{A}=0.014068, \mathrm{~B}=-0.416477$ and $\mathrm{c}$ is the concentration $(\mathrm{v} / \mathrm{v})$. 
Measured differential pressure vs. calculated differential pressure plot is presented at the Figure 6.3.9. Calculated pressure values are close to obtained values from the drag reduction experiments.

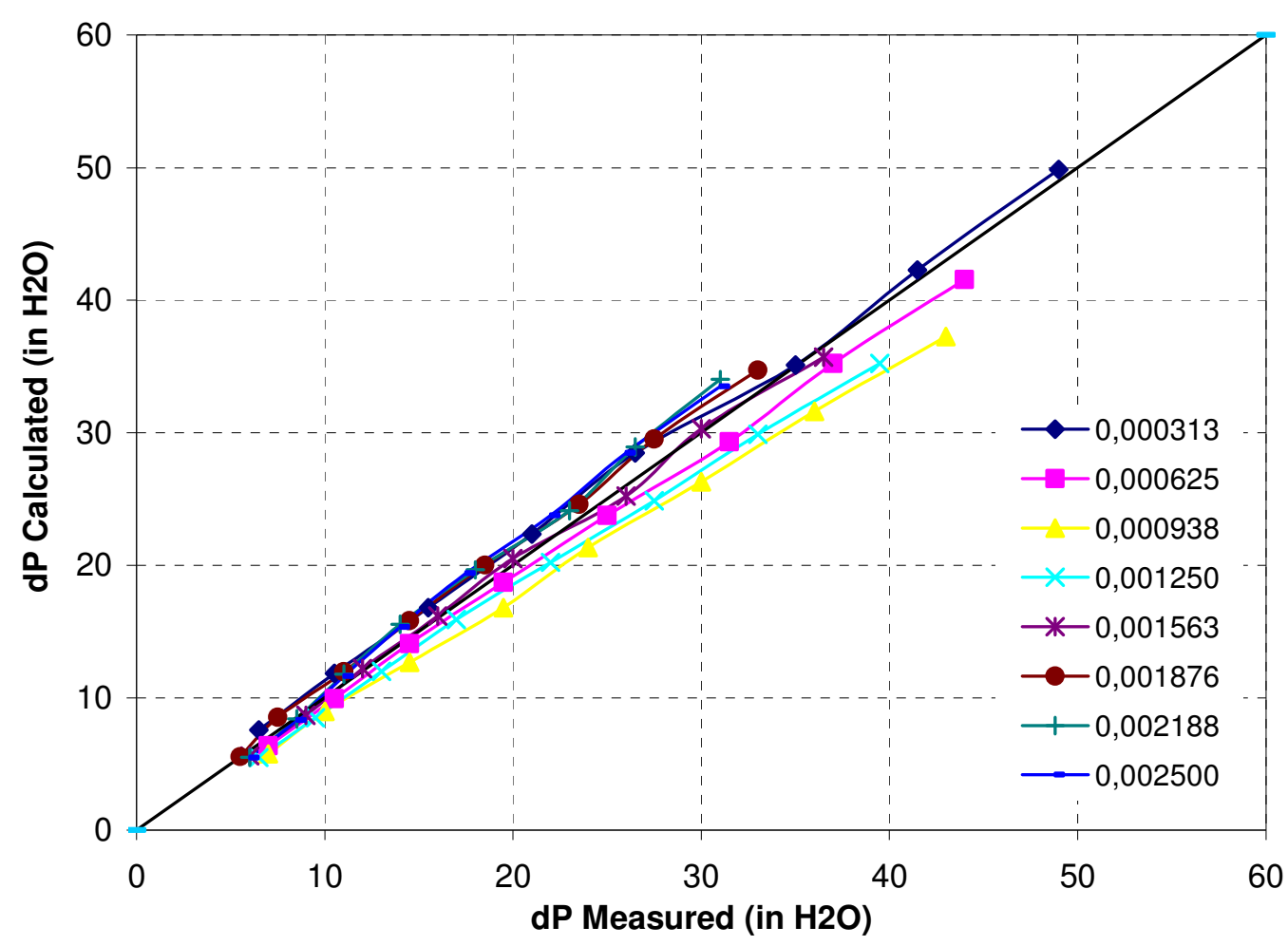

Figure 6.3.9 Measured vs. Calculated Differential Pressure of Correlation

Furthermore, obtained correlation was compared with other correlations from the literature. For that purpose studies of Seyer and Metzner and Shaver and Merrill were utilized.

Friction factor values were calculated with Equations(76) and pressure loss was calculated with Fanning Equation. As it is seen from the Figure 6.3.10, correlation proposed by Seyer and Metzner [17] could not estimate the results obtained from the experiments. The reason for these results is that the viscosities of the solutions and the concentrations obtained at the study of Seyer and Metzner are obtained from the capillary tube viscometer whereas we used rotational viscometer data to calculate Reynolds number for this correlation. 


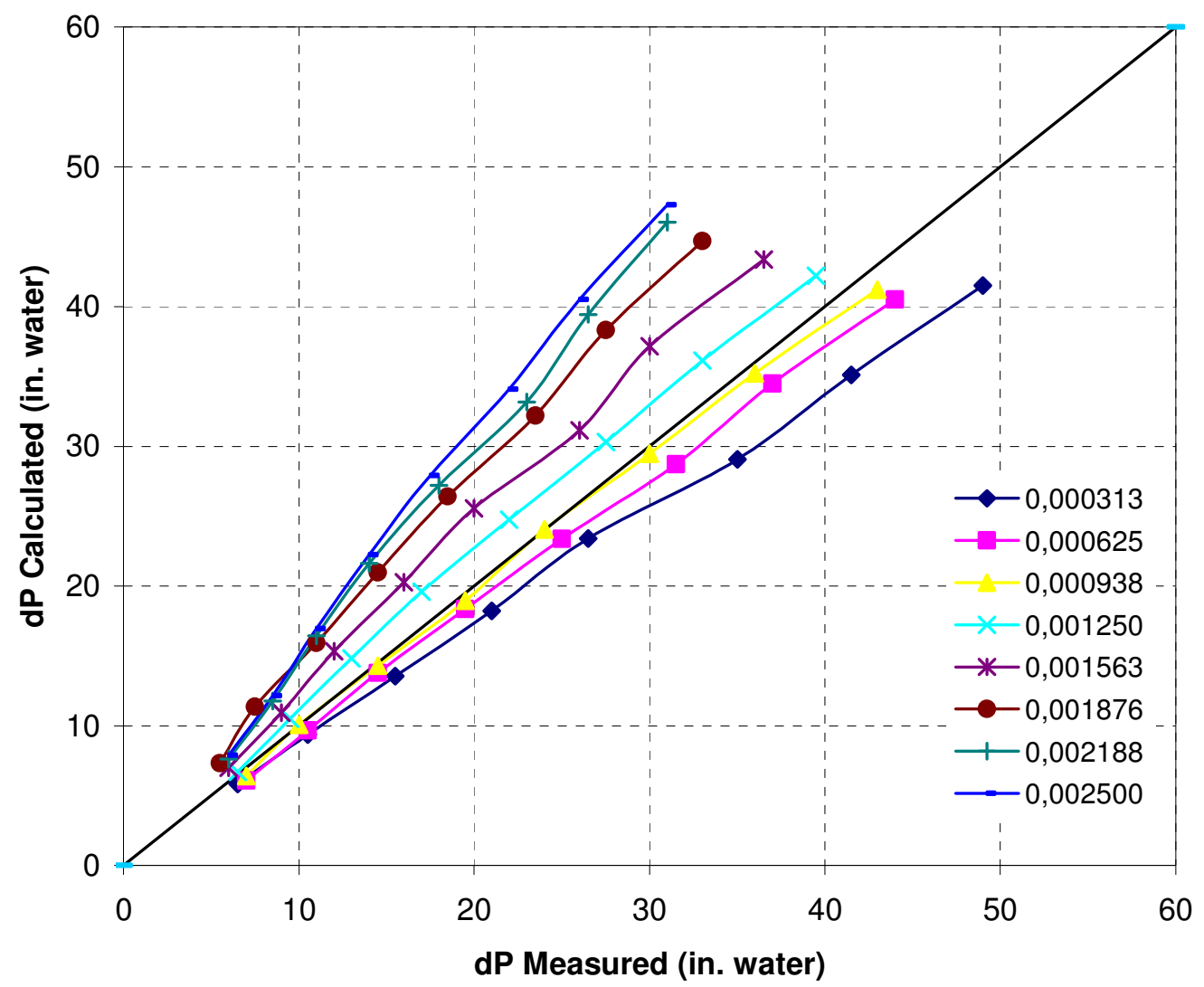

Figure 6.3.10 Measured vs. Calculated Differential Pressure of Seyer and Metzner

Secondly, the study of Shaver and Merrill [2] is used to compare our correlation. Figure 6.3.11 shows a comparison of measured differential pressure and calculated differential pressure for Shaver and Merrill. Friction factor values were calculated with Equation (83) and (84). Again this correlation is not successful to correlate with the experimental results. Shaver and Merrill examined one class of pseudoplastic fluids which are sodium carboxymethylcellulose, ammonium alginate, carboxy-polymethylene and polyisobutylene. These polymers show lower drag reduction compared to polyethyleneoxide and polyacrylamide hence calculated differential pressure values are higher than obtained values from the experiments with EZ-Mud. 


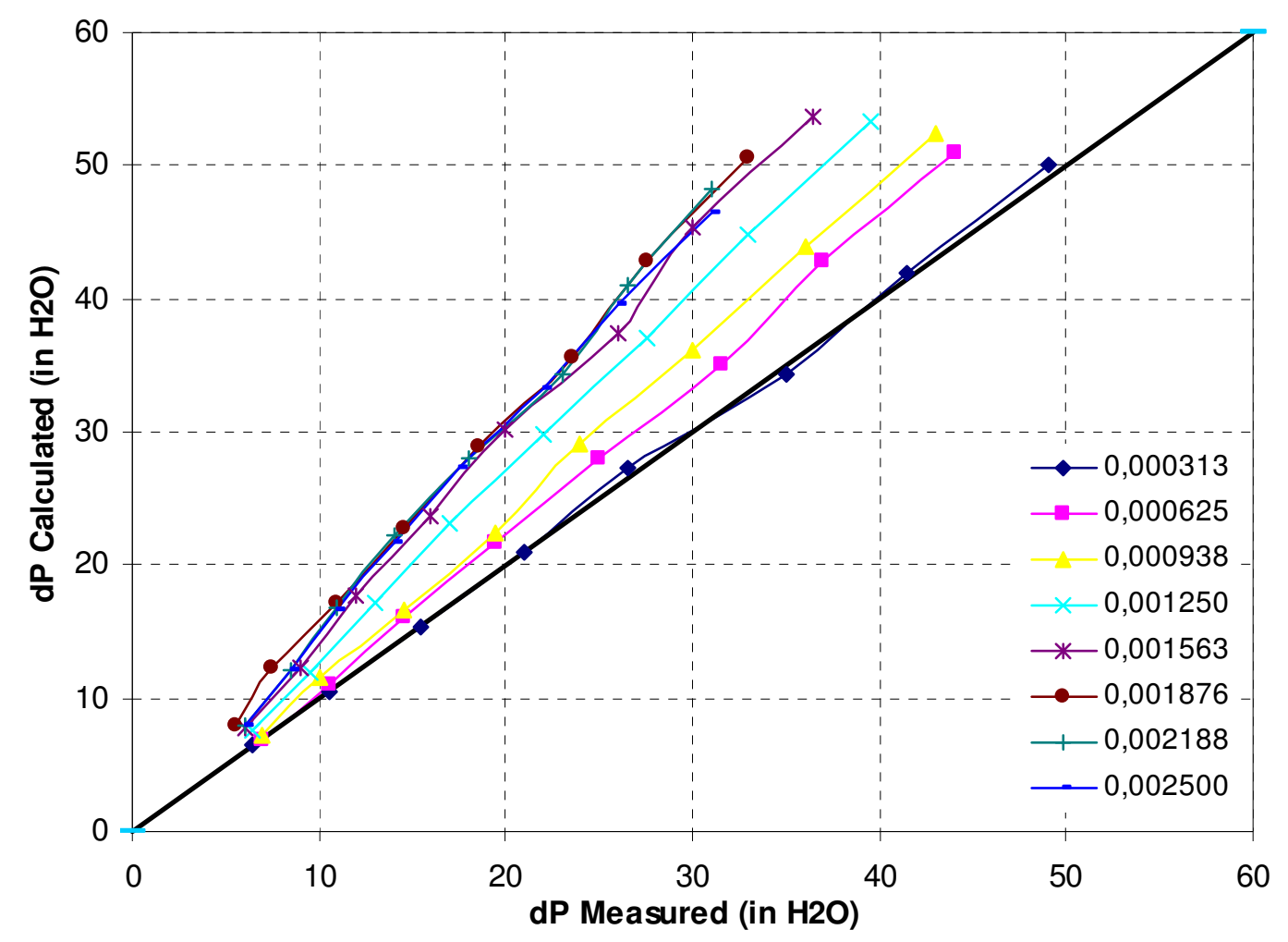

Figure 6.3.11 Measured vs. Calculated Differential Pressure of Shaver and Merrill

When Figures 6.3.9, 6.3.10 and 6.3.11 are compared, it is observed that the proposed correlation can estimate frictional pressure losses significantly better than the existing models. This is because the proposed model not only considers the flow characteristics, but also the concentration of the solution. 


\section{CHAPTER 7}

\section{CONCLUSION}

In this study drag reduction at turbulent pipe flow of EZ-Mud ${ }^{\mathrm{TM}}$, which is a liquid polymer emulsion containing partially hydrolyzed polyacrylamide/polyacrylate (PHPA) copolymer, was investigated. Pipe flow experiments were performed for 8 different concentrations of EZ-Mud ${ }^{\mathrm{TM}}$ and differential pressure data were recorded. Measured pressure drop values were compared with expected differential pressure values and as a result drag reduction was calculated and plotted.

Water experiments were in good agreement with the theoretical values of differential pressure data. Drag reduction experiments were performed successfully. About $60 \%$ drag reduction was achieved during the turbulent pipe flow experiments. Drag reduction was increased with increasing concentration. The optimum EZ-Mud ${ }^{\mathrm{TM}}$ concentration for drag reduction purposes was estimated as $0.0020(\mathrm{v} / \mathrm{v})$. Above this value rheological measurements and pipe flow experiments showed that increasing viscosity might be a major factor preventing further drag reduction. As a result drag reduction capacity of EZ-Mud ${ }^{\mathrm{TM}}$ was presented.

A correlation was obtained to estimate friction factor and differential pressure accordingly for EZ-Mud ${ }^{\mathrm{TM}}$ water system. Estimated pressure drop values were in good agreement with the measured values. The important aspect of the suggested correlations is that it takes concentration into account to estimate pressure losses and the method might be used for different pipe sizes and different polymers. Moreover, measured differential pressure values of drag reduction experiments were compared with two other correlations from the literature. 


\section{RECOMMENDATIONS}

Proposed correlation may be tested and improved by experimental studies with other diameter pipes and other polymers. Besides, further rheological measurements may be performed to obtain a shear rate - shear stress profile which depicts fluid rheology at low shear rates. Hence, it might be possible to decide whether the solutions are Bingham or Power type fluids.

Furthermore, pipe flow experiments may be extended to understand drag reduction properties of EZ-Mud ${ }^{\mathrm{TM}}$ when it is mixed with other drilling materials such as bentonite. 


\section{REFERENCES}

1) B.A. Toms, "Some observations on the flow of linear polymer solutions through straight tubes at large Reynolds number," Proc. First Intern. Congr. on Rheology, vol.II, North Holland Amsterdam, 1948, pp. 135-141.

2) R.G. Shaver, E.W. Merrill, "Turbulent flow of pseudoplastic polymer solutions in straight cylindrical tubes,” AIChE J., vol. 5, 1959, p. 181.

3) A.B. Metzner, "Drag reduction in the turbulent flow of fiber suspensions," AIChE J., vol. 20, 1974, pp. 301-306.

4) Q. Young, J.L. Zakin, "Chemical and rheological characterization of drag reducing cationic surfactant systems," Ind. Eng. Chem. Res., vol. 41, 2002, pp. 6326-6336.

5) C. A. Kim, S. T. Lim, H. J. Choi, J.-I. Sohn, M. S. John, "Characterization of drag reducing guar gum in a rotating disk flow," J. of Applied Polymer Sciences, vol. 83, 2002, pp. 2938-2944.

6) C. A. Kim, H. J. Choi, C. B. Kim, M. S. Jhon, “ Drag reduction characteristics of polysaccharide xanthan gum," Macromol. Rapid Commun, vol.19, No.8, 1998, pp. $419-422$.

7) C. L. Smith, G. Sitaramaiah, "Turbulent drag reduction by polyacrylamide and other polymers," SPE 2405, 1969. 
8) J. H. Sung, C. A. Kim, H. J. Choi, B. K. Hur, J. G. Kim, M. S. Jhon, “Turbulent drag reduction efficiency and mechanical degradation of polyacrylamide," J. of Macromol. Science, Vol. B43, No.2, 2004, pp. 507-518.

9) V. J. Pandey, "Friction pressure correlation for guar based hydraulic fracturing fluids," SPE 71074, presented at the SPE Rocky Mountain Petroleum Technology Conference, Colorado, 2001.

10) C. B. Lester, "Drag reducing agents-2," Oil \& Gas Journal, Feb. 18, 1985.

11) J. A. Lescarboura, J. D. Culter, H. A. Wahl, "Drag reduction with a polymeric additive in crude oil pipelines," SPE 3087, presented at $45^{\text {th }}$ Annual Fall Meeting, Houston, 1971.

12) E. D. Burger, W. R. Munk, H. A. Wahl, "Flow increase in the Trans Alaska Pipeline through use of a polymeric drag reduction additive," J. of Petroleum Technology, SPE 9419, presented at $55^{\text {th }}$ Annual Technical Conference and Exhibition, Dallas, 1982.

13) B. K. Berge, O. Solsvik, "Increased pipeline throughput using drag reduction additives (DRA) field experiences," SPE 36835, presented at European Petroleum Conference, Milan, Italy, 1996.

14) J. G. Savins, "Drag reduction additives improve drilling fluid hydraulics," Oil \& Gas J., Mar.13, 1995.

15) J. G. Savins, "Drag reduction characteristics of solutions of macromolecules in turbulent pipe flow," SPE 867, presented at meeting of AIChE, Houston, Texas 1964.

16) J. G. Oldroyd, "Suggested method of detecting wall effects in turbulent flow through pipes," in Proc. First Intern. Congr. on Rheol., vol. 2, North Holland, Amsterdam, 1948, pp. 130-134. 
17) F. A. Seyer, A. B. Metzner, "Turbulence phenomena in drag reducing systems," AIChE J., vol.15, No.3, 1969.

18) E. G. Richardson, "Dynamics of real fluids," Edward Arnold and Co., London, 1950 .

19) W. A. Meyer, "A correlation of the frictional characteristics for turbulent flow of dilute viscoelastic Non-Newtonian fluids in pipes," AIChE J., vol. 12, No. 3, 1966, p. 522.

20) A. R. Taylor, S. Middleman, "Turbulent Dispersion in drag reducing fluids," AIChE, vol. 20, no. 3, 1974, p. 454.

21) G. Astarita, L. Nicodemo, "Velocity distribution and normal stresses in viscoelastic turbulent pipe flow," AIChE, vol. 12, no. 3, 1966, p. 478.

22) G. K. Patterson, J. L. Zakin, "Prediction of drag reduction with a viscoelastic model," AIChE J., vol. 14, no. 3, 1968, p. 434.

23) J. M. Rodriguez, J. L. Zakin, G. K. Patterson, "Correlation of drag reduction with modified Deborah number for dilute polymer solutions," SPE 1678, presented at Symposium on Mechanics of Rheologically Complex Fluids, Houston, Texas, 1967.

24) R. J. Gordon, "On the explanation and correlation of turbulent drag reduction in dilute macromolecular solutions," J. of Appl. Poly. Science, vol. 14, 1970, pp. 2097-2105.

25) M. T. Landahl, "Dynamics of boundary layer turbulence and the mechanism of drag reduction,” The Physics of Fluids, vol. 20, no. 10, pt. II, Oct. 1977. 
26) R. Darby, H. D. Chang, "Generalized correlation for friction loss in drag reducing polymer solutions," AIChE J., vol. 30, no. 2, 1984, p. 274.

27) P. S. Virk, E. W. Merrill, H. S. Mickley, K. A. Smith, E. L. MolloChristensen," The Toms Phenomenon: Turbulent pipe flow of dilute polymer solutions,” J. of Fluid Mech., vol. 30, 1967, p. 305.

28) P. S. Virk, H. S. Mickley, K. A. Smith, "The ultimate asymptote and mean flow structure in Toms phenomenon," J. of Appl. Mech., vol. 37, Trans. ASME, vol. 92, Series E, no. 2, June 1970, p. 488.

29) P. S. Virk, "Drag reduction fundamentals," AIChE J., vol. 21, no. 4, 1975, p. 625 .

30) N. F. Whitsitt, L. J. Harrington, H. R. Crawford, "Effect of wall shear stress on drag reduction of viscoelastic fluids," Western Co. Report, No. DTMB-3, 1968.

31) J. W. Hoyt, "The effect of additives on fluid friction," Trans. ASME, J. of Basic Engng., vol. 94, 1972, pp. 258-285.

32) K. R. Sreenivasan, C M. White, The onset of drag reduction by dilute polymer additives and the maximum drag reduction asymptote," J. of Fluid Mech., vol. 409, 2000, pp. 149-164.

33) G. C. Liaw, J. L. Zakin, G. K. Patterson, "Effects of molecular characteristics of polymer on drag reduction," AIChE J., vol. 17, no. 2, 1971, p.391.

34) J. M. J. Den Toonder, M. A. Hulsen, G. D. C. Kurken, F. T. M. Nieuwstadt, "Drag reduction by polymer additives in a turbulent pipe flow: numerical and laboratory experiments," J. of Fluid Mech., vol. 337, 1997, pp. 193-231. 
35) C. F. Li, V. K. Gupta, R. Sureshkumar, B. Khomami, "Turbulent channel flow of dilute polymeric solutions: drag reduction scaling and an eddy viscosity model," J. of Non-Newtonian Fluid Mech., vol. 139, 2006, pp. 177-189.

36) H. Oskarsson, I. Uneback, M. Hellston, A. Nobel, "Surfactants as flow improvers in water injection," SPE 93116, presented at International Symposium on Oilfield Chemistry, Houston, Texas, 2005.

37) J. L. Zakin, J. Myska, Z. Chara, "New limiting drag reduction and velocity profile asymptotes for nonpolymeric additives systems," AIChE J., vol. 42, no. 12, 1997, pp. 3544-3546.

38) B. Lu, X. Li, J. L. Zakin, Y. Talman, "A non-viscoelastic drag reducing cationic surfactant system," J. of Non-Newtonian Fluid Mech., vol. 71, 1997, pp. $59-72$.

39) M. W. Liberatory, S. Bark, A. J. McHugh, T. J. Hanratty, “Turbulent drag reduction of polyacrylamide solutions: effect of degradation on molecular weight distribution,” J. of Non-Newtonian Fluid Mech., vol. 123, 2004, pp. 175-183.

40) V. N: Kalashnikov, "Degradation accompanying turbulent drag reduction by polymer additives," J. of Non-Newtonian Fluid Mech., vol. 103, 2002, pp. 105121.

41) C. A. Kim, J. T. Kim, K. Lee, H. J. Choi, M. S. Jhon, "Mechanical degradation of dilute polymer solutions under turbulent flow," Polymer, vol.41, 2000, pp. 7611-7615.

42) W. Brostow, "Drag reduction and mechanical degradation in polymer solutions in flow," Polymer, vol. 24, 1983, p. 631.

43) R. P. Benedict, Fundamentals of pipe flow, New York: Wiley, 1980. 
44) B. Rabinowitch, “Ze Physik Chemie,” vol. A145, 1929, pp. 1-26.

45) M. Mooney, “Journal of Rheology,” vol. 2, 1937, p.210.

46) A. B. Metzner, J. C. Reed, "Flow of non-newtonian fluids - correlation of the laminar, transition, turbulent flow regions," AIChE J., vol. 1, no. 4, 1955, pp. 434440 .

47) D. W. Dodge, A. B. Metzner, "Turbulent flow of non-newtonian systems," AIChE J., vol. 5, no.2, 1959, pp.189-203.

48) B. C. Craft, "Well design, drilling and production," Englewood Cliffs - NJ, Prentice Hall, 1962.

49) J. G. Knudsen, D. L. Katz, "Fluid dynamics and heat transfer," NY, McGraw Hill, 1959.

50) ANSYS CFX v.8.0 Tutorial, "Laminar to Turbulent Flow." 


\section{APPENDIX}

Table A.1 Water Experiments Results

\begin{tabular}{|c|c|c|c|c|c|}
\hline Set & $\mathrm{Q}(\mathrm{gpm})$ & $v(\mathrm{ft} / \mathrm{s})$ & $N_{\mathrm{Re}}$ & $\begin{array}{c}\Delta P_{\text {measured }} \text {, } \\
\text { in. water }\end{array}$ & $\mathrm{ff}$ \\
\hline 1 & 1.00 & 2.32 & 7537 & 4.5 & 0.00849 \\
\hline 1 & 2.00 & 4.63 & 15073 & 10.5 & 0.00714 \\
\hline 1 & 3.00 & 6.95 & 22610 & 21.5 & 0.00645 \\
\hline 1 & 4.00 & 9.26 & 30146 & 36.5 & 0.00600 \\
\hline 1 & 4.80 & 11.12 & 36176 & 49.5 & 0.00574 \\
\hline 2 & 1.50 & 3.47 & 11305 & 6.0 & 0.00767 \\
\hline 2 & 2.00 & 4.63 & 15073 & 10.0 & 0.00714 \\
\hline 2 & 2.50 & 5.79 & 18841 & 15.0 & 0.00675 \\
\hline 2 & 3.00 & 6.95 & 22610 & 21.0 & 0.00645 \\
\hline 2 & 3.50 & 8.11 & 26378 & 27.5 & 0.00621 \\
\hline 2 & 4.00 & 9.26 & 30146 & 37.0 & 0.00600 \\
\hline 2 & 4.50 & 10.42 & 33915 & 45.0 & 0.00583 \\
\hline 3 & 4.00 & 9.26 & 30146 & 37.0 & 0.00600 \\
\hline 3 & 3.50 & 8.11 & 26378 & 28.0 & 0.00621 \\
\hline 3 & 3.00 & 6.95 & 22610 & 21.0 & 0.00645 \\
\hline 3 & 2.50 & 5.79 & 18841 & 15.0 & 0.00675 \\
\hline 3 & 2.00 & 4.63 & 15073 & 10.0 & 0.00714 \\
\hline 3 & 1.50 & 3.47 & 11305 & 6.0 & 0.00767 \\
\hline 4 & 1.50 & 3.47 & 11305 & 7.0 & 0.00767 \\
\hline 4 & 2.00 & 4.63 & 15073 & 11.0 & 0.00714 \\
\hline 4 & 2.50 & 5.79 & 18841 & 16.5 & 0.00675 \\
\hline 4 & 3.00 & 6.95 & 22610 & 23.5 & 0.00645 \\
\hline 4 & 3.50 & 8.11 & 26378 & 30.5 & 0.00621 \\
\hline 4 & 4.00 & 9.26 & 30146 & 38.5 & 0.00600 \\
\hline 4 & 4.20 & 9.73 & 31654 & 41.0 & 0.00593 \\
\hline 5 & 4.00 & 9.26 & 30146 & 39.0 & 0.00600 \\
\hline 5 & 3.50 & 8.11 & 26378 & 30.0 & 0.00621 \\
\hline 5 & 3.00 & 6.95 & 22610 & 23.0 & 0.00645 \\
\hline 5 & 2.50 & 5.79 & 18841 & 16.0 & 0.00675 \\
\hline 5 & 2.00 & 4.63 & 15073 & 11.0 & 0.00714 \\
\hline 5 & 1.50 & 3.47 & 11305 & 7.0 & 0.00767 \\
\hline
\end{tabular}


Table A.2 Rheological Properties of EZ-Mud Solutions

\begin{tabular}{|c|c|c|c|c|c|c|}
\hline Concentration $(\mathrm{v} / \mathrm{v})$ & $\theta 300$ & $\theta 600$ & $\begin{array}{c}\mathrm{PV} \\
(\mathrm{cp})\end{array}$ & $\begin{array}{c}\mathrm{YP} \\
\left(\mathrm{lb} / 100 \mathrm{ft}^{\wedge} 2\right)\end{array}$ & $\mathrm{n}$ & $\mathrm{K}(\mathrm{cp})$ \\
\hline 0.000313 & 1,20 & 2,30 & 1,10 & 0,10 & 0.9381 & 1.76 \\
\hline 0.000625 & 1,60 & 3,00 & 1,40 & 0,20 & 0.9064 & 2.87 \\
\hline 0.000938 & 2,03 & 3,75 & 1,72 & 0,31 & 0.8849 & 4.16 \\
\hline 0.001250 & 2,50 & 4,55 & 2,05 & 0,45 & 0.8634 & 5.85 \\
\hline 0.001563 & 2,98 & 5,35 & 2,37 & 0,61 & 0.8430 & 7.92 \\
\hline 0.001876 & 3,51 & 6,12 & 2,61 & 0,90 & 0.8007 & 12.16 \\
\hline 0.002188 & 4,04 & 6,89 & 2,85 & 1,20 & 0.7686 & 17.09 \\
\hline 0.002500 & 4,57 & 7,65 & 3,08 & 1,49 & 0.7434 & 22.62 \\
\hline
\end{tabular}

Table A.3 Drag Reduction Experiments, Differential Pressure Data (in. water)

\begin{tabular}{|c|c|c|c|c|c|c|c|c|c|}
\hline & & \multicolumn{7}{|c|}{ Concentration (v/v) } \\
\hline Set & Q (gpm) & 0,000313 & 0,000625 & 0,000938 & 0,001250 & 0,001563 & 0,001876 & 0,002188 & 0,002500 \\
\hline & & & & & & & & & \\
\hline 1 & 1.5 & 6.5 & 7.0 & 7.0 & 6.5 & 6.0 & 5.5 & 6.0 & 6.0 \\
\hline 1 & 2.0 & 10.5 & 10.5 & 10.0 & 9.5 & 9.0 & 7.5 & 8.5 & 8.5 \\
\hline 1 & 2.5 & 15.5 & 14.5 & 14.5 & 13.0 & 12.0 & 11.0 & 11.0 & 11.0 \\
\hline 1 & 3.0 & 21.0 & 19.5 & 19.5 & 17.0 & 16.0 & 14.5 & 14.0 & 14.0 \\
\hline 1 & 3.5 & 26.5 & 25.0 & 24.0 & 22.0 & 20.0 & 18.5 & 18.0 & 17.5 \\
\hline 1 & 4.0 & 35.0 & 31.5 & 30.0 & 27.5 & 26.0 & 23.5 & 23.0 & 22.0 \\
\hline 1 & 4.5 & 41.5 & 37.0 & 36.0 & 33.0 & 30.0 & 27.5 & 26.5 & 26.0 \\
\hline 1 & 5.0 & 49.0 & 44.0 & 43.0 & 39.5 & 36.5 & 33.0 & 31.0 & 31.0 \\
\hline 2 & 4.5 & 42.5 & 37.5 & 37.0 & 33.5 & 30.5 & 29.0 & 26.5 & 26.5 \\
\hline 2 & 4.0 & 35.0 & 30.5 & 30.5 & 28.5 & 26.0 & 24.0 & 22.5 & 22.5 \\
\hline 2 & 3.5 & 27.0 & 24.5 & 24.0 & 22.5 & 20.5 & 19.5 & 18.0 & 18.0 \\
\hline 2 & 3.0 & 21.0 & 19.5 & 19.0 & 18.3 & 16.5 & 15.0 & 14.5 & 14.5 \\
\hline 2 & 2.5 & 16.0 & 15.0 & 14.5 & 14.0 & 12.5 & 12.0 & 11.5 & 11.5 \\
\hline 2 & 2.0 & 11.0 & 10.5 & 10.5 & 10.0 & 9.5 & 9.0 & 8.5 & 9.0 \\
\hline 2 & 1.5 & 7.0 & 7.0 & 7.0 & 6.5 & 6.5 & 6.0 & 6.5 & 6.0 \\
\hline
\end{tabular}


Table A.4 Percent Drag Reduction Based on Bingham Law

\begin{tabular}{|c|c|c|c|c|c|c|c|c|c|}
\hline & & \multicolumn{7}{|c|}{ Concentration (v/v) } \\
\hline Set & Q gpm & 0,000313 & 0,000625 & 0,000938 & 0,00125 & 0,001563 & 0,001876 & 0,002188 & 0,0025 \\
\hline & & & & & & & & & \\
\hline 1 & 1,5 & 4,3 & 3,9 & 9,3 & 20,0 & 29,2 & 37,5 & 34,1 & 36,0 \\
\hline 1 & 2,0 & 6,1 & 12,3 & 21,1 & 28,6 & 35,1 & 47,8 & 42,6 & 44,2 \\
\hline 1 & 2,5 & 6,0 & 17,7 & 22,2 & 33,5 & 41,0 & 47,7 & 49,2 & 50,5 \\
\hline 1 & 3,0 & 7,3 & 19,3 & 23,7 & 36,5 & 42,6 & 49,6 & 52,7 & 53,9 \\
\hline 1 & 3,5 & 10,5 & 20,9 & 28,1 & 37,1 & 45,0 & 50,7 & 53,3 & 55,7 \\
\hline 1 & 4,0 & 6,4 & 21,0 & 28,7 & 37,6 & 43,3 & 50,2 & 52,6 & 55,7 \\
\hline 1 & 4,5 & 9,6 & 24,4 & 30,3 & 39,0 & 46,6 & 52,5 & 55,4 & 57,3 \\
\hline 1 & 5,0 & 11,2 & 25,1 & 30,7 & 39,2 & 45,9 & 52,5 & 56,5 & 57,5 \\
\hline 2 & 4,5 & 7,4 & 23,4 & 28,3 & 38,1 & 45,7 & 49,9 & 55,4 & 56,5 \\
\hline 2 & 4,0 & 6,4 & 23,5 & 27,5 & 35,4 & 43,3 & 49,2 & 53,6 & 54,7 \\
\hline 2 & 3,5 & 8,8 & 22,5 & 28,1 & 35,7 & 43,6 & 48,0 & 53,3 & 54,5 \\
\hline 2 & 3,0 & 7,3 & 19,3 & 25,6 & 31,9 & 40,8 & 47,9 & 51,0 & 52,2 \\
\hline 2 & 2,5 & 3,0 & 14,9 & 22,2 & 28,4 & 38,6 & 43,0 & 46,9 & 48,3 \\
\hline 2 & 2,0 & 1,7 & 12,3 & 17,1 & 24,8 & 31,5 & 37,3 & 42,6 & 40,9 \\
\hline 2 & 1,5 & $-3,1$ & 3,9 & 9,3 & 20,0 & 23,3 & 31,9 & 28,6 & 36,0 \\
\hline
\end{tabular}

Table A.5 Percent Drag Reduction Based on Power Law

\begin{tabular}{|c|c|c|c|c|c|c|c|c|c|c|}
\hline & & \multicolumn{7}{|c|}{ Concentration (v/v) } \\
\hline Set & Q gpm & 0,000313 & 0,000625 & 0,000938 & 0,001250 & 0,001563 & 0,001876 & 0,002188 & 0,002500 \\
\hline 1 & 1,5 & 5,8 & 6,2 & 11,9 & 22,6 & 31,9 & 40,4 & 37,5 & 39,6 \\
\hline 1 & 2,0 & 7,6 & 14,3 & 23,3 & 31,0 & 37,5 & 50,2 & 45,6 & 47,3 \\
\hline 1 & 2,5 & 7,4 & 19,5 & 24,3 & 35,6 & 43,1 & 50,0 & 51,8 & 53,2 \\
\hline 1 & 3,0 & 8,6 & 21,0 & 25,6 & 38,4 & 44,5 & 51,7 & 54,9 & 56,2 \\
\hline 1 & 3,5 & 11,7 & 22,4 & 29,7 & 38,8 & 46,7 & 52,6 & 55,3 & 57,8 \\
\hline 1 & 4,0 & 7,5 & 22,4 & 30,2 & 39,2 & 44,9 & 52,0 & 54,5 & 57,6 \\
\hline 1 & 4,5 & 10,6 & 25,6 & 31,6 & 40,4 & 48,0 & 54,0 & 57,0 & 58,9 \\
\hline 1 & 5,0 & 12,0 & 26,2 & 31,9 & 40,4 & 47,2 & 53,9 & 57,9 & 59,0 \\
\hline 2 & 4,5 & 8,4 & 24,6 & 29,7 & 39,5 & 47,1 & 51,5 & 57,0 & 58,2 \\
\hline 2 & 4,0 & 7,5 & 24,8 & 29,1 & 37,0 & 44,9 & 51,0 & 55,5 & 56,7 \\
\hline
\end{tabular}


Table A.5 (Continued)

\begin{tabular}{|l|c|c|c|c|c|c|c|c|c|}
\hline 2 & 3,5 & 10,0 & 23,9 & 29,7 & 37,4 & 45,4 & 50,0 & 55,3 & 56,6 \\
\hline 2 & 3,0 & 8,6 & 21,0 & 27,5 & 33,9 & 42,8 & 50,0 & 53,3 & 54,6 \\
\hline 2 & 2,5 & 4,4 & 16,8 & 24,3 & 30,6 & 40,8 & 45,5 & 49,6 & 51,1 \\
\hline 2 & 2,0 & 3,2 & 14,3 & 19,5 & 27,3 & 34,1 & 40,2 & 45,6 & 44,2 \\
\hline 2 & 1,5 & $-1,4$ & 6,2 & 11,9 & 22,6 & 26,2 & 35,0 & 32,3 & 39,6 \\
\hline
\end{tabular}

